\title{
Performances and Reliability of Bruker Microflex LT and VITEK MS MALDI-TOF Mass Spectrometry Systems for the Identification of Clinical Microorganisms
}

\author{
Kivanc Bilecen, ${ }^{1}$ Gorkem Yaman, ${ }^{2}$ Ugur Ciftci, ${ }^{3}$ and Yahya Rauf Laleli ${ }^{3}$ \\ ${ }^{1}$ Department of Research \& Development, Duzen Laboratories Group, 06680 Ankara, Turkey \\ ${ }^{2}$ Department of Clinical Microbiology, Duzen Laboratories Group, 34387 Istanbul, Turkey \\ ${ }^{3}$ Department of Clinical Microbiology, Duzen Laboratories Group, 06680 Ankara, Turkey \\ Correspondence should be addressed to Kivanc Bilecen; kivanc.bilecen@gmail.com
}

Received 1 September 2015; Revised 14 November 2015; Accepted 16 November 2015

Academic Editor: Qaisar Mahmood

Copyright ( 2015 Kivanc Bilecen et al. This is an open access article distributed under the Creative Commons Attribution License, which permits unrestricted use, distribution, and reproduction in any medium, provided the original work is properly cited.

\begin{abstract}
In clinical microbiology laboratories, routine microbial identification is mostly performed using culture based methodologies requiring 24 to 72 hours from culturing to identification. Matrix assisted laser desorption ionization-time of flight mass spectrometry (MALDI-TOF MS) technology has been established as a cost effective, reliable, and faster alternative identification platform. In this study, we evaluated the reliability of the two available MALDI-TOF MS systems for their routine clinical level identification accuracy and efficiency in a clinical microbiology laboratory setting. A total of 1,341 routine phenotypically identified clinical bacterial and fungal isolates were selected and simultaneously analyzed using VITEK MS (bioMérieux, France) and Microflex LT (Bruker Diagnostics, Germany) MALDI-TOF MS systems. For any isolate that could not be identified with either of the systems and for any discordant result, $16 \mathrm{~S}$ rDNA gene or ITS1/ITS2 sequencing was used. VITEK MS and Microflex LT correctly identified 1,303 (97.17\%) and 1,298 (96.79\%) isolates to the species level, respectively. In 114 (8.50\%) isolates initial phenotypic identification was inaccurate. Both systems showed a similar identification efficiency and workflow robustness, and they were twice as more accurate compared to routine phenotypic identification in our sample pool. MALDITOF systems with their accuracy and robustness offer a good identification platform for routine clinical microbiology laboratories.
\end{abstract}

\section{Introduction}

Rapid and accurate identification of bacteria and yeasts from clinical specimens is crucial for the effective management of infections. In the clinical microbiology laboratories, microbial identification is conventionally done by phenotypic and biochemical analyses mostly using automated systems. These analyses require time ranging from a few hours to several days depending on microbial species in question. Workload and cost requirements for molecular methods, although they provide faster and accurate results, limit their routine use in clinical microbiology laboratories.

MALDI-TOF MS technology makes generation of unique mass spectral fingerprints of microorganisms possible, which are mostly a snapshot of ribosomal proteins ideal for an accurate microbial identification at the species level [1].
MALDI-TOF MS can rapidly and accurately identify a wide range of microorganisms at a reasonable cost using only a portion or the entire colony and a drop of matrix solution. While the MALDI-TOF MS analysis for the identification of intact bacterial cells was demonstrated 17 years ago $[2,3]$ and was extended to eukaryotic fungal cells 13 years ago $[4,5]$, not until recently has its potential for routine use been assessed for identification of a wide spectrum of bacteria, yeasts, molds, and mycobacteria that can be isolated in the clinical laboratories [6-13]. The ability of MALDI-TOF MS to directly identify bacteria in positive blood cultures is also important for the effective management of bloodstream infections [14, 15].

By this mean, two different $\mathrm{CE}$ marked in vitro diagnostic (IVD) MALDI TOF-MS systems were implemented to our laboratories in Ankara and Istanbul in March, 2012, and since 
then they have been used as the main identification tool for routine clinical bacterial and yeast isolates. In this study we evaluated performances of Bruker Microflex LT (Bruker Daltonics, Germany) and VITEK MS (bioMérieux, France) MALDI TOF-MS systems for identification of routine clinical microbiology isolates.

\section{Materials and Methods}

2.1. Clinical Isolates and Collection Strains. A total of 1,341 routine clinical isolates including 1,181 bacterial and 160 fungal specimens were analyzed using VITEK MS and Bruker Microflex LT. The isolates were obtained from clinical specimens including urine, blood, tissue, wounds, bronchoalveolar lavage, tracheal aspirate, sputum and wounds, which had been sent to our laboratory from various intensive care units, health facilities, and laboratories between April 2012 and December 2013. No selection criteria was applied for the isolates in order to obtain a comprehensive diversity.

Both MALDI-TOF MS systems were verified using 18 certified reference microorganisms obtained from reference culture collections.

\subsection{Culture Conditions and Identification of Microorganisms.} The specimens were routinely inoculated to appropriate media like, Columbia agar with $5 \%$ sheep blood, eosin methylene blue (EMB) agar, chromogenic urinary tract infection (CUTI) medium, chocolate agar, oxacillin resistant screening agar (ORSA), Salmonella-shigella agar, Thayer-Martin agar, Candida chromogenic agar, and blood culture bottles at $37^{\circ} \mathrm{C}$ depending on specimen type.

All of the specimens were incubated overnight at $37^{\circ} \mathrm{C}$. The isolates were then Gram stained and identified using the reciprocate cards of VITEK II (bioMérieux, France) automated microbial identification system. The cultures and phenotypic identification results were transported to Ankara Duzen Laboratory Microbiology Department for VITEK MS analyses.

The strains were prepared and identified with VITEK MS system in Ankara and the results were documented. Following these initial identifications, culture plates were transported to our Clinical Laboratory Department located in İstanbul under appropriate conditions for the next day analysis with Bruker Microflex LT system.

2.3. VITEK MS MALDI-TOF System. From the overnight appropriate agar plates a portion or the whole colony was smeared onto the spots of VITEK MS-DS disposable target slides and then the spot was covered with $1 \mu \mathrm{L}$ of $\alpha$-cyano-4hidroxycinnamic acid (CHCA) matrix solution. Spots were completely air dried, and, then, the slides were placed on an adapter and inserted to VITEK MS instrument. Spectra were generated using the MYLA software (bioMérieux, France) and the identification was automatically done with the VITEK MS IVD version 2.4.0-5 software. This software version contains $>25,000$ spectra, covering 586 species consisting of 508 bacteria and 78 fungi in its database. The software compares the spectrum obtained to the expected spectrum of each organism or organism group. Then the percent probability, a quantitative value, is calculated for each sample. The range of percent probabilities for a correct identification is from 60 to 99 with values closer to 99.9 indicating a closer match. When the obtained percent probability is under 60 , then it was considered as noidentification. Confidence level is determined with percent probability and number of choices. During our analyses, although there was a unique identification pattern within the good confidence level, a list of possible organisms was given for certain samples. In such cases if both organisms belonged to the same genus then this result was accepted as a reliable identification to the genus level. In some other cases, when the strain belonged to a complex (e.g., Enterobacter cloacae complex) these results were documented as a correct result according to the cutoff value of the system; however the identification to the complex level was documented in order to compare the performances of the two systems accurately.

2.4. Bruker Microflex LT System. A portion or the whole colony was directly transferred onto the 96 spotted polished steel target plate. The spot was covered with $1 \mu \mathrm{L}$ of CHCA matrix solution. After completely air drying, the plate was loaded to the Microflex LT instrument. The spectra were generated in linear positive ion mode with delayed extraction in a mass range of 4 to $10 \mathrm{kDa}$ using a $337 \mathrm{~nm}$ nitrogen laser with a frequency of $60 \mathrm{~Hz}$. The automated data analysis was processed with MALDI Biotyper Realtime Classification and Biotyper software version 3.0 (Bruker Daltonics). The obtained spectra were analyzed by standard patternmatching algorithm, which compared the raw spectra with the spectra of the Bruker library by using the standard setting, and the results were listed in a ranking table. The results were expressed as log (score) values, which ranged from 0 to 3 as recommended by the manufacturer. Score values of $>1.7$ generally indicated relationships at the genus level, and values of $>2.0$ generally indicated relationships at the species level. The highest score was used for species identification. The Bruker library contains $>80,000$ spectra covering 2,048 species and 385 genera. If the result was below 1.7 then the extraction method was performed where the colony was transferred into $1.5-\mathrm{mL}$ screw cap tubes and mixed thoroughly in $0.3 \mathrm{~mL}$ of double-distilled ultrapure water. $0.9 \mathrm{~mL}$ of pure ethanol was added to tubes and after vortexing they were centrifuged at $13,000 \times \mathrm{g}$ for $2 \mathrm{~min}$. The supernatant was discarded and the pellet was mixed thoroughly with $50 \mu \mathrm{L}$ of $70 \%$ aqueous formic acid. After the addition of $50 \mu \mathrm{L}$ of acetonitrile, the mixture was centrifuged at $13,000 \times \mathrm{g}$ for $2 \mathrm{~min}$. One microliter of the microorganism extract supernatant was placed onto the polished steel and covered with $1 \mu \mathrm{L}$ of CHCA matrix solution and loaded to the instrument.

2.5. Discordant Results. Results obtained from VITEK MS and Microflex LT were compared to initial onsite phenotypic identification results. The decision matrix used for the comparison and classification of results is given in Table 1. Briefly, when MS and the onsite phenotypic identification 


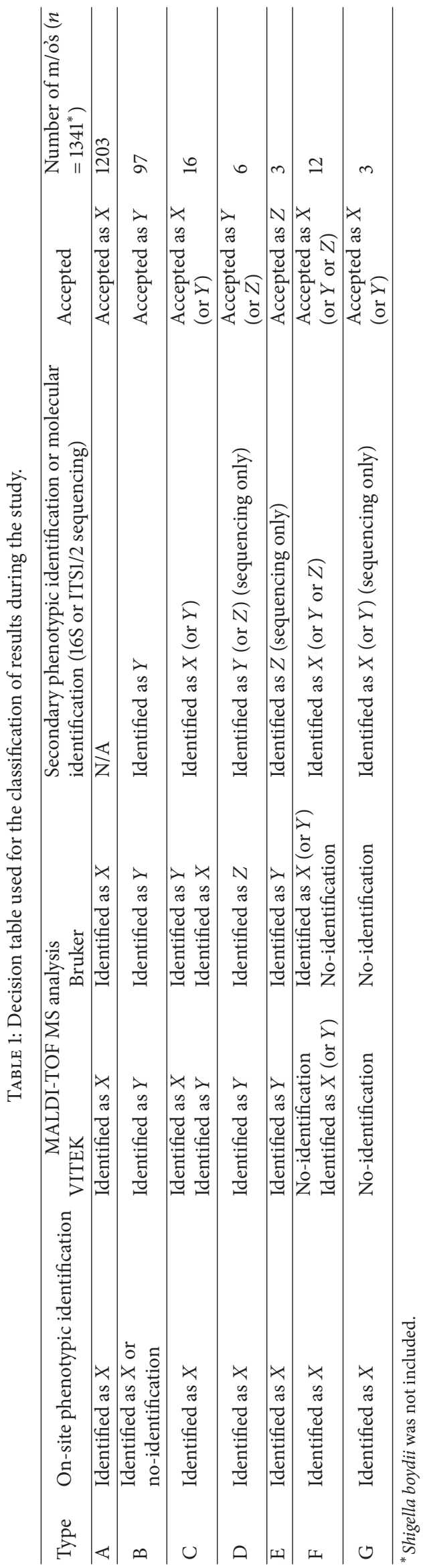


results agreed at the species level, then this was accepted as a correct result at the species level. When any MS equipment gave a correct result but as a species complex, then this was considered as a correct result and specified in the result table. For any discordant with the onsite phenotypic identification result we performed a second phenotypic identification. If this second phenotypic identification agreed with the MS result then this second result is accepted depending on correctness level, species, or genus. Otherwise a $16 \mathrm{~S}$ or ITS1/2 sequencing analysis was performed depending on the nature of microorganism (prokaryote or eukaryote).

2.6. Extraction and Purification of Genomic DNA. Three to four colonies were selected from agar plates, resuspended in $500 \mu \mathrm{L} 1 \mathrm{x}$ PBS ( $\mathrm{pH} 7.4$ ), and used for genomic DNA isolation. Genomic DNA isolation from Gram-negative bacteria was performed using DNA4U Bacterial Genomic DNA Isolation Kit (NANObiz, Turkey) as instructed by the manufacturer. DNA isolation from Gram-positive bacteria and other microorganisms were performed using conventional phenol/chloroform extraction method. Briefly, samples in $500 \mu \mathrm{L} \mathrm{1x}$ PBS were centrifuged at $12,500 \mathrm{~g}$ for 5 minutes, resuspended in sterile water, recentrifuged, and resuspended in $500 \mu \mathrm{L}$ TES buffer (50 mM Tris-HCl, pH 8.0; 1 mM EDTA; $6.7 \%$ sucrose). For Gram-positive bacteria $75 \mu \mathrm{L}$ of $10 \mathrm{mg} / \mathrm{mL}$ lysozyme was added and samples were incubated at $37^{\circ} \mathrm{C}$ for 1 hour. After the incubation $125 \mu \mathrm{L}$ of $20 \%$ SDS was added into each sample and incubated at $37^{\circ} \mathrm{C}$ for 30 minutes. Later $700 \mu \mathrm{L}$ of phenol (SIGMA, USA) was added and samples were gently mixed using a vortex. Samples were then centrifuged at 2,000 rpm for 5 minutes and aqueous phases were removed into clean microcentrifuge tubes. Equal amount of $24: 1(\mathrm{v} / \mathrm{v})$ chloroform: isoamyl alcohol was added and centrifuged at 2,000 rpm for 5 minutes. Aqueous phase was again removed into a clean microcentrifuge tube, and first 0.1 volume of ice cold $3 \mathrm{M}$ potassium acetate, $\mathrm{pH} 5.5$, and then 2 volumes of ice cold absolute ethanol were added. Samples were then incubated at $-80^{\circ} \mathrm{C}$ for 15 minutes. Ethanol was removed through centrifugation at $10,000 \mathrm{rpm}$ for 15 minutes, and this ethanol wash was repeated once more. Obtained pellets were then incubated at $50^{\circ} \mathrm{C}$ for approximately 15 minutes. Dry pellets were resuspended in $50 \mu \mathrm{L}$ of sterile water. Purified genomic DNA was either visualized via agarose gel electrophoresis or directly measured for absorbance at $260 \mathrm{~nm}$.

2.7. PCR Amplification of $16 S$ Regions. The forward primer S-D-Bact-0008-a-S-20 (5'-AGA GTT TGA TCC TGG CTC $\left.\mathrm{AG}-3^{\prime}\right)$ [16] and the reverse primer $\mathrm{rP} 2\left(5^{\prime}\right.$-ACG GCT ACC TTG TTA CGA CTT-3') [17], which target the domain Bacteria, were used to amplify bacterial $16 \mathrm{~S}$ rDNA sequences by PCR. Reaction mixture for PCR contained 1x PCR buffer (Fermentas), $2.0 \mathrm{mM} \mathrm{MgCl} 2,200 \mu \mathrm{M}$ dNTP (each), $200 \mathrm{ng}$ template genomic DNA, $0.5 \mu \mathrm{M}$ of each primer, and 1.0 U Taq polymerase (Fermentas). DNA denaturation and amplification cycles were performed as described [16] using GeneAmp PCR System 9700 thermocycler (Applied
Biosystems). Amplification products were checked via agarose gel electrophoresis.

2.8. PCR Amplification of ITS Regions. ITS1 (5'-TCCGTAGGTGAACCTGCGG- $3^{\prime}$ ) and ITS4 (5' -TCCTCCGCTTATTGATATGC- $3^{\prime}$ ) primers were used to amplify internal transcribed spacer regions 1 and 2 of microorganisms [18]. Reaction mixture for PCR contained 1x PCR buffer (Fermentas), $1.5 \mathrm{mM} \mathrm{MgCl}_{2}, 100 \mu \mathrm{M}$ dNTP (each), $0.5 \mu \mathrm{M}$ of each primer, and 1.0 U Taq polymerase (Fermentas) to a final concentration of $15 \mu \mathrm{L}$. DNA denaturation and amplification cycles were performed as described [18].

2.9. DNA Sequencing and Sequence Analyses. PCR products were sequenced via Sanger sequencing using 3130 Genetic Analyzer (Applied Biosystems). Obtained sequences were compared to $16 \mathrm{~S} \mathrm{rDNA}$ and/or ITS sequences that are found in public databases: NCBI (http://blast.ncbi.nlm.nih.gov/) and Green Genes 16S rDNA (http://greengenes.lbl.gov/).

\section{Results}

3.1. Reference Microorganisms. Eighteen reference bacterial strains were tested (Table 2) for verification and comparison of both MALDI-TOF MS systems. Salmonella typhimurium (ATCC 202165), Salmonella enteritidis (DM10), and Salmonella enterica subsp. enterica serovar typhimurium (ATCC 14028) were identified only to the genus level as Salmonella spp. These were all expected as they are within the current MALDI-TOF system limitations [1]. The rest of the reference microorganisms could all be accurately identified to the species level (Table 2).

3.2. Routine Clinical Bacterial Isolates. Our results indicated that both MS systems had high accuracy in the identification of routine clinical bacterial isolates that cover a wide range of species known to cause human infections (Tables 3 and 4). VITEK MS correctly identified 916 (77.56\%) clinical bacterial isolates to the species and 231 (19.56\%) isolates to the clinically relevant species group, totaling 1,147 (97.12\%) correct identification on the species level. From the same pool, Bruker Microflex LT identified 1,142 (96.70\%) clinical isolates to the species level.

Identification on genus only level was also similar for both systems. VITEK MS could identify 19 (1.61\%) and Bruker Microflex LT could identify 28 (2.37\%) isolates only to the genus level. Genus level, but not to species level identification of Salmonella spp. $(n=15)$ accounts for the main decrease in the percentage for correct species level identification for both systems, which is a known system limitation.

Misidentification numbers were similar for VITEK MS and Bruker Microflex LT with $5(0.42 \%)$ and $4(0.33 \%)$ isolates, respectively. Shigella boydii was incorrectly identified as $E$. coli by both systems, but this is also a known system limitation.

Except one Leuconostoc mesenteroides isolate, the remaining misidentified isolates were identified by at least one system. L. mesenteroides was misidentified as Staphylococcus 
TABLE 2: Results of 18 reference bacterial strains that were analyzed by VITEK MS and Bruker Microflex LT for an initial system setup and comparison.

\begin{tabular}{|c|c|c|}
\hline Microorganism & VITEK & Bruker \\
\hline $\begin{array}{l}\text { S. pyogenes } \\
\text { ATCC } 19615\end{array}$ & $\checkmark$ & $\checkmark$ \\
\hline $\begin{array}{l}\text { E. coli } \\
\text { ATCC } 25922\end{array}$ & $\checkmark$ & $\checkmark$ \\
\hline $\begin{array}{l}\text { K. pneumoniae } \\
\text { ATCC } 13883\end{array}$ & $\checkmark$ & $\checkmark$ \\
\hline $\begin{array}{l}\text { P. aeruginosa } \\
\text { ATCC } 27853\end{array}$ & $\checkmark$ & $\checkmark$ \\
\hline $\begin{array}{l}\text { S. aureus } \\
\text { ATCC } 25923\end{array}$ & $\checkmark$ & $\checkmark$ \\
\hline $\begin{array}{l}\text { S. pneumoniae } \\
\text { ATCC } 49619\end{array}$ & $\checkmark$ & $\checkmark$ \\
\hline $\begin{array}{l}\text { P. vulgaris } \\
\text { ATCC } 13315\end{array}$ & P. vulgaris/penneri & $\begin{array}{c}\text { P. hauseri } \\
\text { (new nomenclature) }\end{array}$ \\
\hline $\begin{array}{l}\text { S. typhimurium } \\
\text { ATCC } 14028\end{array}$ & Salmonella group & Salmonella spp. \\
\hline $\begin{array}{l}\text { Y. enterocolitica } \\
\text { ATCC } 9610\end{array}$ & $\checkmark$ & $\checkmark$ \\
\hline $\begin{array}{l}V . \text { cholera } \\
\text { RSKK } 913\end{array}$ & $\checkmark$ & $\begin{array}{c}\checkmark \\
\text { (V. cholerae biovar } \\
\text { albensis) }\end{array}$ \\
\hline $\begin{array}{l}\text { G. vaginalis } \\
\text { DM } 108\end{array}$ & $\checkmark$ & $\checkmark$ \\
\hline $\begin{array}{l}\text { S. saprophyticus } \\
\text { DM } 17\end{array}$ & $\checkmark$ & $\checkmark$ \\
\hline $\begin{array}{l}\text { S. agalactiae } \\
\text { DM } 20\end{array}$ & $\checkmark$ & $\checkmark$ \\
\hline $\begin{array}{l}\text { MRSA } \\
\text { DM } 66\end{array}$ & S. aureus & S. aureus \\
\hline $\begin{array}{l}\text { S. epidermidis } \\
\text { DM } 19\end{array}$ & $\checkmark$ & $\checkmark$ \\
\hline $\begin{array}{l}\text { S. enteritidis } \\
\text { DM } 10\end{array}$ & Salmonella group & Salmonella spp. \\
\hline $\begin{array}{l}\text { A. hydrophila } \\
\text { DM } 110\end{array}$ & A. hydrophila/caviae & A. caviae \\
\hline $\begin{array}{l}\text { P. shigelloides } \\
\text { DM } 111\end{array}$ & $\checkmark$ & $\checkmark$ \\
\hline
\end{tabular}

pettenkoferi by Bruker Microflex LT, whereas it could not be identified by VITEK MS.

A total of three isolates, Wautersiella falsenii, Kluyvera cryocrescens, and Corynebacterium glaucum, could not be identified by both systems (Table 4 ).

3.3. Fungal Samples. We have observed a very similar identification accuracy in both systems. Out of 160 fungal samples VITEK MS correctly identified 155 (96.88\%) isolates to the species, $1(0.62 \%)$ isolate to the species complex, and $3(1.88 \%)$ isolates to the genus level. Similarly, Bruker Microflex LT identified 156 (97.50\%) fungal isolates to the species level and $4(2.50 \%)$ isolates to the genus level.

There was no misidentification in both systems. VITEK MS could not identify an Aspergillus brasiliensis isolate as this microorganism is not present in the system's library, whereas Bruker Microflex LT identified this isolate to the species level.

\section{Discussion}

Our results indicated that, using any of the two available MALDI-TOF MS systems, a species level correct identification accuracy of over $96 \%$ could be achieved without any prior information about the tested samples. We have reached this high accuracy level using the regular sample extraction methods without any strain specific pretreatment in order to determine the efficiency of MS systems in the routine clinical microbiology settings.

In our laboratory, conventional biochemistry based phenotypic microbial identification methods costs about $\$ 15$ and typically takes from 6 to 18 hours depending on the tested microorganisms. MALDI-TOF MS system, on the other hand, requires only 5 to 30 minutes for the identification and it costs less than $\$ 1$ per sample.

For this study we collected various clinical specimens which were sent to our laboratory with an initial on-site identification that had been carried out using a VITEK II Compact phenotypic identification platform. During our analyses; for 97 (7.23\%) isolates both MS systems gave a different result than this initial on-site phenotypic identification. Our further molecular (16S or ITS1/2 sequencing) or phenotypic analysis resulted in favor of MS systems for all of these 97 isolates. Additional 17 (0.01\%) isolates were also confirmed to be different than the on-site phenotypic identification and these isolates were misidentified at least by one of the MS systems. As a result, a total of $114(8.50 \%)$ isolates were misidentified by phenotypic methods, whereas an average of $37(2.76 \%)$ isolates were misidentified or could not be identified by MS systems used in this study, making them at least twice as more accurate (Table 6). Using the wrong ID card and in some few instances wrong labeling might account for these incorrect on-site identifications. MS systems, as they do not need prior strain information, proved themselves more accurate and efficient for this instance.

Identification of microorganisms using a MALDI-TOF system is based on prerecorded protein spectra that are present in the system library [19]. These spectra are mainly based on ribosomal proteins and therefore MALDI-TOF systems have intrinsic limitations to differentiate closely related species or strains such as Salmonella spp. In our study the number of identification on the genus only level was 19 (1.61\%) for VITEK MS and 28 (2.37\%) for Bruker Microflex LT, mainly due to this systems' limitations. Genus level, but not to species level, identification of Salmonella spp. $(n=15)$ accounts for the main decrease in the percentage for species level correct identification for both systems.

When we compared the identification accuracies of the two systems we have seen similar results. However we have 


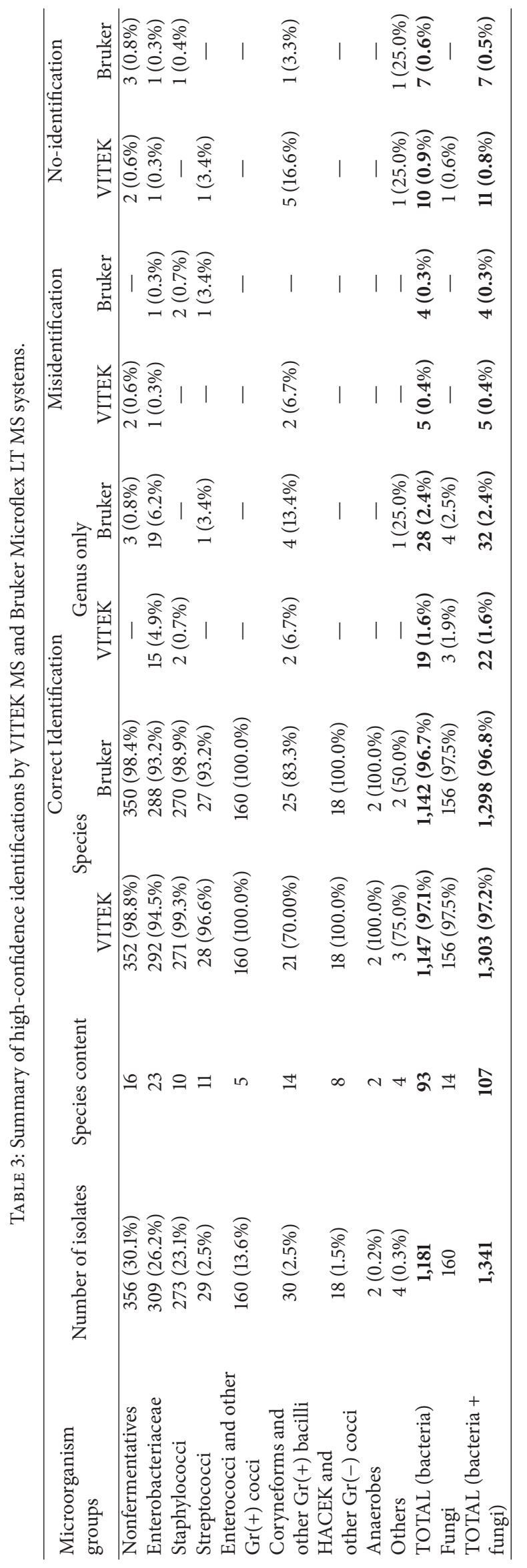


TABLE 4: High-confidence identifications by VITEK MS and Bruker Microflex LT MS systems.

\begin{tabular}{|c|c|c|c|c|c|c|c|c|c|c|}
\hline \multirow{4}{*}{$\begin{array}{l}\text { Microorganism } \\
\text { groups }\end{array}$} & \multirow{4}{*}{$\begin{array}{c}\text { \# of } \\
\text { isolates }\end{array}$} & \multicolumn{5}{|c|}{ Correct Identification } & \multicolumn{2}{|c|}{ Misidentification } & \multicolumn{2}{|c|}{ No-identification } \\
\hline & & \multirow{2}{*}{\multicolumn{2}{|c|}{ Species }} & \multicolumn{3}{|c|}{ Genus only } & \multirow{3}{*}{ VITEK } & \multirow{3}{*}{ Bruker } & \multirow{3}{*}{ VITEK } & \multirow{3}{*}{ Bruker } \\
\hline & & & & Bruker & VITEK & Bruker & & & & \\
\hline & & Species & Species Complex & & & & & & & \\
\hline \multicolumn{11}{|c|}{ Nonfermentatives (16 species) } \\
\hline $\begin{array}{l}\text { Achromobacter } \\
\text { xylosoxidans }\end{array}$ & 6 & 4 & 2 & 6 & - & - & - & - & - & - \\
\hline $\begin{array}{l}\text { Acinetobacter } \\
\text { baumannii }\end{array}$ & 194 & - & 192 & 192 & - & - & - & - & $\begin{array}{c}2 \\
(\mathrm{~F} \times 2)\end{array}$ & $\begin{array}{c}2 \\
(\mathrm{~F} \times 2)\end{array}$ \\
\hline $\begin{array}{l}\text { Acinetobacter } \\
\text { guillouiae }\end{array}$ & 1 & - & 1 & 1 & - & - & - & - & - & - \\
\hline $\begin{array}{l}\text { Acinetobacter } \\
\text { johnsonii }\end{array}$ & 1 & 1 & - & 1 & - & - & - & - & - & - \\
\hline $\begin{array}{l}\text { Acinetobacter } \\
\text { lwoffii }\end{array}$ & 1 & 1 & - & 1 & - & - & - & - & - & - \\
\hline $\begin{array}{l}\text { Acinetobacter } \\
\text { radioresistens }\end{array}$ & 1 & 1 & - & 1 & - & - & - & - & - & - \\
\hline $\begin{array}{l}\text { Aeromonas } \\
\text { hydrophila }\end{array}$ & 3 & - & 3 & 2 & - & $1(\mathrm{C})$ & - & - & - & - \\
\hline Aeromonas sobria & 1 & - & 1 & - & - & - & - & - & - & $\begin{array}{c}1 \\
(\mathrm{~F})\end{array}$ \\
\hline Alcaligenes faecalis & 2 & 2 & - & 2 & - & - & - & - & - & - \\
\hline $\begin{array}{l}\text { Burkholderia } \\
\text { cepacia }\end{array}$ & 2 & - & 2 & - & - & $2(\mathrm{C} \times 2)$ & - & - & - & - \\
\hline $\begin{array}{l}\text { Comamonas } \\
\text { aquatica }\end{array}$ & 1 & - & - & 1 & - & - & $1(\mathrm{D})$ & - & - & - \\
\hline Delftia acidovorans & 3 & 3 & - & 3 & - & - & - & - & - & - \\
\hline $\begin{array}{l}\text { Elizabethkingia } \\
\text { meningoseptica }\end{array}$ & 1 & 1 & - & 1 & - & - & - & - & - & - \\
\hline $\begin{array}{l}\text { Pseudomonas } \\
\text { aeruginosa }\end{array}$ & 125 & 124 & - & 125 & - & - & $1(\mathrm{C})$ & - & - & - \\
\hline $\begin{array}{l}\text { Pseudomonas } \\
\text { fluorescens }\end{array}$ & 1 & 1 & - & 1 & - & - & - & - & - & - \\
\hline $\begin{array}{l}\text { Stenotrophomonas } \\
\text { maltophilia }\end{array}$ & 13 & 13 & - & 13 & - & - & - & - & - & - \\
\hline Total & 356 & $\begin{array}{c}151 \\
(42.4 \%)\end{array}$ & $201(56.4 \%)$ & $350(98.4 \%)$ & - & $3(0.8 \%)$ & $2(0.6 \%)$ & - & $\begin{array}{c}2 \\
(0.6 \%)\end{array}$ & $\begin{array}{c}3 \\
(0.8 \%)\end{array}$ \\
\hline \multicolumn{11}{|c|}{ Enterobacteriaceae (23 species) } \\
\hline $\begin{array}{l}\text { Chryseobacterium } \\
\text { indologenes }\end{array}$ & 1 & 1 & - & 1 & - & - & - & - & - & - \\
\hline Citrobacter braakii & 3 & - & 3 & 3 & - & - & - & - & - & - \\
\hline Citrobacter freundii & 5 & 3 & 2 & 5 & - & - & - & - & - & - \\
\hline Citrobacter sedlakii & 1 & 1 & - & 1 & - & - & - & - & - & - \\
\hline $\begin{array}{l}\text { Citrobacter } \\
\text { youngae }\end{array}$ & 2 & - & 2 & 1 & - & $1(\mathrm{C})$ & - & - & - & - \\
\hline $\begin{array}{l}\text { Enterobacter } \\
\text { aerogenes }\end{array}$ & 4 & 4 & - & 4 & - & - & - & - & - & - \\
\hline $\begin{array}{l}\text { Enterobacter } \\
\text { asburiae }\end{array}$ & 2 & - & 2 & 1 & - & $1(\mathrm{C})$ & - & - & - & - \\
\hline $\begin{array}{l}\text { Enterobacter } \\
\text { cancerogenous }\end{array}$ & 1 & 1 & - & 1 & - & - & - & - & - & - \\
\hline $\begin{array}{l}\text { Enterobacter } \\
\text { cloacae }\end{array}$ & 11 & - & 11 & 9 & - & $2(\mathrm{C} \times 2)$ & - & - & - & - \\
\hline
\end{tabular}


TABle 4: Continued.

\begin{tabular}{|c|c|c|c|c|c|c|c|c|c|c|}
\hline \multirow{4}{*}{$\begin{array}{l}\text { Microorganism } \\
\text { groups }\end{array}$} & \multirow{4}{*}{$\begin{array}{c}\text { \# of } \\
\text { isolates }\end{array}$} & \multicolumn{5}{|c|}{ Correct Identification } & \multicolumn{2}{|c|}{ Misidentification } & \multicolumn{2}{|c|}{ No-identification } \\
\hline & & \multicolumn{3}{|c|}{ Species } & \multicolumn{2}{|c|}{ Genus only } & \multirow{3}{*}{ VITEK } & \multirow{3}{*}{ Bruker } & \multirow{3}{*}{ VITEK } & \multirow{3}{*}{ Bruker } \\
\hline & & \multicolumn{2}{|c|}{ VITEK } & Bruker & VITEK & Bruker & & & & \\
\hline & & Species & Species Complex & & & & & & & \\
\hline Escherichia coli & 123 & 123 & - & 123 & - & - & - & - & - & - \\
\hline Klebsiella oxytoca & 5 & 5 & - & 5 & - & - & - & - & - & - \\
\hline $\begin{array}{l}\text { Klebsiella } \\
\text { pneumonia }\end{array}$ & 64 & 64 & - & 64 & - & - & - & - & - & - \\
\hline $\begin{array}{l}\text { Kluyvera } \\
\text { cryocrescens }\end{array}$ & 1 & - & - & - & - & - & - & - & $\begin{array}{c}1 \\
(\mathrm{G})\end{array}$ & $1(\mathrm{G})$ \\
\hline $\begin{array}{l}\text { Morganella } \\
\text { morganii }\end{array}$ & 12 & 12 & - & 12 & - & - & - & - & - & - \\
\hline Proteus mirabilis & 28 & 28 & - & 28 & - & - & - & - & - & - \\
\hline Providencia rettgeri & 3 & 3 & - & 3 & - & - & - & - & - & - \\
\hline Providencia stuartii & 1 & 1 & - & 1 & - & - & - & - & - & - \\
\hline $\begin{array}{l}\text { Raoultella } \\
\text { ornithinolytica }\end{array}$ & 3 & 2 & 1 & 3 & - & - & - & - & - & - \\
\hline $\begin{array}{l}\text { Raoultella } \\
\text { planticola }\end{array}$ & 1 & - & 1 & 1 & - & - & - & - & - & - \\
\hline Salmonella spp. & 15 & - & - & - & 15 & 15 & - & - & - & - \\
\hline $\begin{array}{l}\text { Serratia } \\
\text { liquefaciens }\end{array}$ & 1 & 1 & - & 1 & - & - & - & - & - & - \\
\hline Serratia marcescens & 21 & 21 & - & 21 & - & - & - & - & - & - \\
\hline Shigella boydii & 1 & - & - & - & - & - & 1 (N/A) & $\begin{array}{c}1 \\
(\mathrm{~N} / \mathrm{A})\end{array}$ & - & - \\
\hline Total & 309 & $\begin{array}{c}270 \\
(87.4 \%)\end{array}$ & $22(7.1 \%)$ & $288(93.3 \%)$ & $15(4.9 \%)$ & $19(6.1 \%)$ & $1(0.3 \%)$ & $\begin{array}{c}1 \\
(0.3 \%)\end{array}$ & $\begin{array}{c}1 \\
(0.3 \%)\end{array}$ & $\begin{array}{c}1 \\
(0.3 \%)\end{array}$ \\
\hline & & & Stal & phylococci (10 & species) & & & & & \\
\hline $\begin{array}{l}\text { Staphylococcus } \\
\text { aureus }\end{array}$ & 52 & 52 & - & 52 & - & - & - & - & - & - \\
\hline $\begin{array}{l}\text { Staphylococcus } \\
\text { capitis }\end{array}$ & 8 & 8 & - & 8 & - & - & - & - & - & - \\
\hline $\begin{array}{l}\text { Staphylococcus } \\
\text { caprae }\end{array}$ & 1 & 1 & - & 1 & - & - & - & - & - & - \\
\hline $\begin{array}{l}\text { Staphylococcus } \\
\text { epidermidis }\end{array}$ & 68 & 68 & - & 65 & - & - & - & $\begin{array}{c}2 \\
(\mathrm{C} \times 2)\end{array}$ & - & $1(\mathrm{~F})$ \\
\hline $\begin{array}{l}\text { Staphylococcus } \\
\text { haemolyticus }\end{array}$ & 54 & 54 & - & 54 & - & - & - & - & - & - \\
\hline $\begin{array}{l}\text { Staphylococcus } \\
\text { hominis }\end{array}$ & 82 & 82 & - & 82 & - & - & - & - & - & - \\
\hline $\begin{array}{l}\text { Staphylococcus } \\
\text { lugdunensis }\end{array}$ & 1 & 1 & - & 1 & - & - & - & - & - & - \\
\hline $\begin{array}{l}\text { Staphylococcus } \\
\text { pettenkoferi }\end{array}$ & 1 & - & - & 1 & $1(\mathrm{C})$ & - & - & - & - & - \\
\hline $\begin{array}{l}\text { Staphylococcus } \\
\text { sciuri }\end{array}$ & 2 & 2 & - & 2 & - & - & - & - & - & - \\
\hline $\begin{array}{l}\text { Staphylococcus } \\
\text { simulans }\end{array}$ & 4 & 3 & - & 4 & $1(\mathrm{D})$ & - & - & - & - & - \\
\hline Total & 273 & $\begin{array}{c}271 \\
(99.3 \%)\end{array}$ & - & $270(98.9 \%)$ & $2(0.7 \%)$ & - & - & $\begin{array}{c}2 \\
(0.7 \%)\end{array}$ & - & $\begin{array}{c}1 \\
(0.4 \%)\end{array}$ \\
\hline
\end{tabular}


TABle 4: Continued.

\begin{tabular}{|c|c|c|c|c|c|c|c|c|c|c|}
\hline \multirow{4}{*}{$\begin{array}{l}\text { Microorganism } \\
\text { groups }\end{array}$} & \multirow{4}{*}{$\begin{array}{c}\text { \# of } \\
\text { isolates }\end{array}$} & \multicolumn{5}{|c|}{ Correct Identification } & \multicolumn{2}{|c|}{ Misidentification } & \multicolumn{2}{|c|}{ No-identification } \\
\hline & & \multicolumn{3}{|c|}{ Species } & \multicolumn{2}{|c|}{ Genus only } & \multirow{3}{*}{ VITEK } & \multirow{3}{*}{ Bruker } & \multirow{3}{*}{ VITEK } & \multirow{3}{*}{ Bruker } \\
\hline & & & EK & Bruker & VITEK & Bruker & & & & \\
\hline & & Species & Species Complex & & & & & & & \\
\hline \multicolumn{11}{|c|}{ Streptococci (11 species) } \\
\hline $\begin{array}{l}\text { Leuconostoc } \\
\text { mesenteroides }\end{array}$ & 1 & - & - & - & - & - & - & $1(\mathrm{~F})$ & $\begin{array}{c}1 \\
(\mathrm{~F})\end{array}$ & - \\
\hline $\begin{array}{l}\text { Streptococcus } \\
\text { agalactiae }\end{array}$ & 9 & 9 & - & 9 & - & - & - & - & - & - \\
\hline $\begin{array}{l}\text { Streptococcus } \\
\text { anginosus }\end{array}$ & 1 & 1 & - & 1 & - & - & - & - & - & - \\
\hline $\begin{array}{l}\text { Streptococcus } \\
\text { dysgalactiae }\end{array}$ & 3 & 3 & - & 3 & - & - & - & - & - & - \\
\hline $\begin{array}{l}\text { Streptococcus } \\
\text { gallolyticus }\end{array}$ & 1 & 1 & - & 1 & - & - & - & - & - & - \\
\hline Streptococcus mitis & 1 & - & 1 & - & - & $1(\mathrm{C})$ & - & - & - & - \\
\hline Streptococcus oralis & 1 & - & 1 & 1 & - & - & - & - & - & - \\
\hline $\begin{array}{l}\text { Streptococcus } \\
\text { parasanguinis }\end{array}$ & 1 & 1 & - & 1 & - & - & - & - & - & - \\
\hline $\begin{array}{l}\text { Streptococcus } \\
\text { pneumonia }\end{array}$ & 4 & 4 & - & 4 & - & - & - & - & - & - \\
\hline $\begin{array}{l}\text { Streptococcus } \\
\text { pyogenes }\end{array}$ & 6 & 6 & - & 6 & - & - & - & - & - & - \\
\hline $\begin{array}{l}\text { Streptococcus } \\
\text { salivarius }\end{array}$ & 1 & 1 & - & 1 & - & - & - & - & - & - \\
\hline Total & 29 & $\begin{array}{c}26 \\
(89.7 \%) \\
\end{array}$ & $2(6.9 \%)$ & $27(93.2 \%)$ & - & $1(3.4 \%)$ & - & $\begin{array}{c}1 \\
(3.4 \%) \\
\end{array}$ & $\begin{array}{c}1 \\
(3.4 \%) \\
\end{array}$ & - \\
\hline \multicolumn{11}{|c|}{ Enterococci and other $\mathrm{Gr}(+)$ cocci (5 species) } \\
\hline Aerococcus viridans & 4 & 4 & - & 4 & - & - & - & - & - & - \\
\hline Enterococcus avium & 4 & 4 & - & 4 & - & - & - & - & - & - \\
\hline $\begin{array}{l}\text { Enterococcus } \\
\text { faecalis }\end{array}$ & 54 & 54 & - & 54 & - & - & - & - & - & - \\
\hline $\begin{array}{l}\text { Enterococcus } \\
\text { faecium }\end{array}$ & 84 & 84 & - & 84 & - & - & - & - & - & - \\
\hline $\begin{array}{l}\text { Enterococcus } \\
\text { gallinarum }\end{array}$ & 14 & 14 & - & 14 & - & - & - & - & - & - \\
\hline Total & 160 & $\begin{array}{c}160 \\
(100 \%) \\
\end{array}$ & - & $160(100 \%)$ & - & - & - & - & - & - \\
\hline \multicolumn{11}{|c|}{ Coryneforms and other $\mathrm{Gr}(+)$ bacilli (14 species) } \\
\hline $\begin{array}{l}\text { Actinomyces } \\
\text { naeslundii }\end{array}$ & 1 & - & - & - & - & $1(\mathrm{~F})$ & - & - & $\begin{array}{c}1 \\
(\mathrm{~F})\end{array}$ & - \\
\hline Bacillus cereus & 1 & - & 1 & 1 & - & - & - & - & - & - \\
\hline Bacillus simplex & 1 & 1 & - & 1 & - & - & - & - & - & - \\
\hline $\begin{array}{l}\text { Corynebacterium } \\
\text { amycolatum }\end{array}$ & 4 & - & 4 & 4 & - & - & - & - & - & - \\
\hline $\begin{array}{l}\text { Corynebacterium } \\
\text { appendicis }\end{array}$ & 1 & - & - & - & $1(\mathrm{E})$ & $1(\mathrm{E})$ & - & - & - & - \\
\hline $\begin{array}{l}\text { Corynebacterium } \\
\text { coyleae }\end{array}$ & 1 & - & - & 1 & - & - & 1 (D) & - & - & - \\
\hline $\begin{array}{l}\text { Corynebacterium } \\
\text { glaucum }\end{array}$ & 1 & - & - & - & - & - & - & - & $\begin{array}{c}1 \\
(\mathrm{G})\end{array}$ & $1(\mathrm{G})$ \\
\hline $\begin{array}{l}\text { Corynebacterium } \\
\text { jeikeium }\end{array}$ & 2 & 2 & - & 2 & - & - & - & - & - & - \\
\hline $\begin{array}{l}\text { Corynebacterium } \\
\text { mucifaciens }\end{array}$ & 3 & - & - & 3 & - & - & 1 (D) & - & $\begin{array}{c}2 \\
(\mathrm{~F})\end{array}$ & - \\
\hline $\begin{array}{l}\text { Corynebacterium } \\
\text { striatum }\end{array}$ & 10 & 10 & - & 10 & - & - & - & - & - & - \\
\hline
\end{tabular}


TABLE 4: Continued.

\begin{tabular}{|c|c|c|c|c|c|c|c|c|c|c|}
\hline \multirow{4}{*}{$\begin{array}{l}\text { Microorganism } \\
\text { groups }\end{array}$} & \multirow{4}{*}{$\begin{array}{l}\text { \# of } \\
\text { isolates }\end{array}$} & \multicolumn{5}{|c|}{ Correct Identification } & \multicolumn{2}{|c|}{ Misidentification } & \multicolumn{2}{|c|}{ No-identification } \\
\hline & & \multicolumn{3}{|c|}{ Species } & \multicolumn{2}{|c|}{ Genus only } & \multirow{3}{*}{ VITEK } & \multirow{3}{*}{ Bruker } & \multirow{3}{*}{ VITEK } & \multirow{3}{*}{ Bruker } \\
\hline & & \multicolumn{2}{|c|}{ VITEK } & Bruker & VITEK & Bruker & & & & \\
\hline & & Species & Species Complex & & & & & & & \\
\hline $\begin{array}{l}\text { Corynebacterium } \\
\text { urealyticum }\end{array}$ & 1 & 1 & - & 1 & - & - & - & - & - & - \\
\hline $\begin{array}{l}\text { Corynebacterium } \\
\text { ureicelerivorans }\end{array}$ & 2 & - & - & - & $1(\mathrm{E})$ & $2(\mathrm{E}, \mathrm{F})$ & - & - & $\begin{array}{c}1 \\
(\mathrm{~F})\end{array}$ & - \\
\hline $\begin{array}{l}\text { Lactobacillus } \\
\text { paracasei }\end{array}$ & 1 & - & 1 & 1 & - & - & - & - & - & - \\
\hline $\begin{array}{l}\text { Listeria } \\
\text { monocytogenes }\end{array}$ & 1 & 1 & - & 1 & - & - & - & - & - & - \\
\hline Total & 30 & $\begin{array}{c}15 \\
(50.0 \%) \\
\end{array}$ & $6(20.0 \%)$ & $25(83.4 \%)$ & $2(6.7 \%)$ & $4(13.3 \%)$ & $2(6.7 \%)$ & - & $\begin{array}{c}5 \\
(16.6 \%) \\
\end{array}$ & $\begin{array}{c}1 \\
(3.3 \%) \\
\end{array}$ \\
\hline \multicolumn{11}{|c|}{ HACEK and other $\operatorname{Gr}(-)$ cocci (8 species) } \\
\hline $\begin{array}{l}\text { Haemophilus } \\
\text { haemolyticus }\end{array}$ & 1 & 1 & - & 1 & - & - & - & - & - & - \\
\hline $\begin{array}{l}\text { Haemophilus } \\
\text { influenza }\end{array}$ & 3 & 3 & - & 3 & - & - & - & - & - & - \\
\hline $\begin{array}{l}\text { Haemophilus } \\
\text { parahaemolyticus }\end{array}$ & 2 & 2 & - & 2 & - & - & - & - & - & - \\
\hline $\begin{array}{l}\text { Haemophilus } \\
\text { parainfluenzae }\end{array}$ & 1 & 1 & - & 1 & - & - & - & - & - & - \\
\hline $\begin{array}{l}\text { Legionella } \\
\text { pneumophila }\end{array}$ & 7 & 7 & - & 7 & - & - & - & - & - & - \\
\hline $\begin{array}{l}\text { Moraxella } \\
\text { catarrhalis }\end{array}$ & 1 & 1 & - & 1 & - & - & - & - & - & - \\
\hline $\begin{array}{l}\text { Neisseria } \\
\text { meningitides }\end{array}$ & 1 & 1 & - & 1 & - & - & - & - & - & - \\
\hline $\begin{array}{l}\text { Pasteurella } \\
\text { multocida }\end{array}$ & 2 & 2 & - & 2 & - & - & - & - & - & - \\
\hline Total & 18 & $\begin{array}{c}18 \\
(100 \%)\end{array}$ & - & $18(100 \%)$ & - & - & - & - & - & - \\
\hline \multicolumn{11}{|c|}{ Anaerobes (2 species) } \\
\hline $\begin{array}{l}\text { Clostridium } \\
\text { perfringens }\end{array}$ & 1 & 1 & - & 1 & - & - & - & - & - & - \\
\hline $\begin{array}{l}\text { Clostridium } \\
\text { sporogenes }\end{array}$ & 1 & 1 & - & 1 & - & - & - & - & - & - \\
\hline Total & 2 & $\begin{array}{c}2 \\
(100 \%)\end{array}$ & - & $2(100 \%)$ & - & - & - & - & - & - \\
\hline \multicolumn{11}{|c|}{ Others (4 species) } \\
\hline $\begin{array}{l}\text { Bergeyella } \\
\text { zoohelcum }\end{array}$ & 1 & 1 & - & 1 & - & - & - & - & - & - \\
\hline $\begin{array}{l}\text { Myroides } \\
\text { odoratimimus }\end{array}$ & 1 & 1 & - & - & - & $1(\mathrm{C})$ & - & - & - & - \\
\hline Rhodococcus equi & 1 & 1 & - & 1 & - & - & - & - & - & - \\
\hline $\begin{array}{l}\text { Wautersiella } \\
\text { falsenii }\end{array}$ & 1 & - & - & - & - & - & - & - & $1(\mathrm{G})$ & $1(\mathrm{G})$ \\
\hline Total & 4 & $\begin{array}{c}3 \\
(75.0 \%) \\
\end{array}$ & - & $2(50.0 \%)$ & - & $1(\mathrm{C})(25.0 \%)$ & - & - & $\begin{array}{c}1(G) \\
(25.0 \%)\end{array}$ & $\begin{array}{c}1(G) \\
(25.0 \%)\end{array}$ \\
\hline Total (bacteria) & 1,181 & $\begin{array}{c}916 \\
(77.6 \%) \\
\end{array}$ & $231(19.6 \%)$ & $1,142(96.7 \%)$ & $19(1.6 \%)$ & $28(2.4 \%)$ & $5(0.4 \%)$ & $\begin{array}{c}4 \\
(0.3 \%) \\
\end{array}$ & $\begin{array}{c}10 \\
(0.8 \%) \\
\end{array}$ & $\begin{array}{c}7 \\
(0.6 \%) \\
\end{array}$ \\
\hline
\end{tabular}


TABLE 4: Continued.

\begin{tabular}{|c|c|c|c|c|c|c|c|c|c|c|}
\hline \multirow{4}{*}{$\begin{array}{l}\text { Microorganism } \\
\text { groups }\end{array}$} & \multirow{4}{*}{$\begin{array}{l}\text { \# of } \\
\text { isolates }\end{array}$} & \multicolumn{5}{|c|}{ Correct Identification } & \multicolumn{2}{|c|}{ Misidentification } & \multicolumn{2}{|c|}{ No-identification } \\
\hline & & \multirow{2}{*}{\multicolumn{2}{|c|}{ VITEK }} & \multicolumn{3}{|c|}{ Genus only } & \multirow{3}{*}{ VITEK } & \multirow{3}{*}{ Bruker } & \multirow{3}{*}{ VITEK } & \multirow{3}{*}{ Bruker } \\
\hline & & & & Bruker & VITEK & Bruker & & & & \\
\hline & & Species & Species Complex & & & & & & & \\
\hline \multicolumn{11}{|c|}{ Fungi (14 species) } \\
\hline $\begin{array}{l}\text { Aspergillus } \\
\text { brasiliensis }\end{array}$ & 1 & - & - & 1 & - & - & - & - & $1(\mathrm{~F})$ & - \\
\hline Candida albicans & 43 & 43 & - & 41 & - & $2(\mathrm{C} \times 2)$ & - & - & - & - \\
\hline $\begin{array}{l}\text { Candida } \\
\text { dubliniensis }\end{array}$ & 1 & 1 & - & 1 & - & - & - & - & - & - \\
\hline Candida glabrata & 44 & 44 & - & 44 & - & - & - & - & - & - \\
\hline Candida kefyr & 11 & 11 & - & 11 & - & - & - & - & - & - \\
\hline Candida krusei & 4 & 4 & - & 4 & - & - & - & - & - & - \\
\hline Candida lusitaniae & 2 & 2 & - & 2 & - & - & - & - & - & - \\
\hline $\begin{array}{l}\text { Candida } \\
\text { norvegensis }\end{array}$ & 1 & 1 & - & 1 & - & - & - & - & - & - \\
\hline $\begin{array}{l}\text { Candida } \\
\text { orthopsilosis }\end{array}$ & 2 & - & - & 2 & $2(\mathrm{D} \times 2)$ & - & - & - & - & - \\
\hline $\begin{array}{l}\text { Candida } \\
\text { parapsilosis }\end{array}$ & 14 & 14 & - & 13 & - & $1(\mathrm{C})$ & - & - & - & - \\
\hline Candida tropicalis & 32 & 31 & 1 & 32 & & & & & & \\
\hline $\begin{array}{l}\text { Cryptococcus } \\
\text { neoformans }\end{array}$ & 1 & 1 & - & 1 & - & - & - & - & - & - \\
\hline $\begin{array}{l}\text { Meyerozyma } \\
\text { caribbica }\end{array}$ & 1 & - & - & - & $1(\mathrm{E})$ & $1(\mathrm{E})$ & - & - & - & - \\
\hline Trichosporon asahii & 3 & 3 & - & 3 & - & - & - & - & - & - \\
\hline Total (fungi) & 160 & $\begin{array}{c}155 \\
(96.9 \%)\end{array}$ & $1(0.6 \%)$ & $156(97.5 \%)$ & $3(1.9 \%)$ & $4(2.5 \%)$ & - & - & $\begin{array}{c}1 \\
(0.6 \%)\end{array}$ & - \\
\hline \multirow[t]{2}{*}{$\begin{array}{l}\text { TOTAL (bacteria }+ \\
\text { fungi) }\end{array}$} & \multirow[t]{2}{*}{1,341} & $\begin{array}{c}1,071 \\
(79.9 \%)\end{array}$ & $232(17.3 \%)$ & $1,298(96.8 \%)$ & $22(1.6 \%)$ & $32(2.4 \%)$ & $5(0.4 \%)$ & \multirow[t]{2}{*}{$\begin{array}{c}4 \\
(0.3 \%)\end{array}$} & \multirow[t]{2}{*}{$\begin{array}{c}11 \\
(0.8 \%)\end{array}$} & \multirow[t]{2}{*}{$\begin{array}{c}7 \\
(0.5 \%)\end{array}$} \\
\hline & & 1,30 & $03(97.2 \%)$ & & & & & & & \\
\hline
\end{tabular}

observed a relatively higher number of correct genera but wrong species count for the Bruker Microflex LT especially with closely related genera or complex members. VITEK MS prefer to give multiple results as species complexes leading to fewer errors while dealing with close species like Streptococcus parasanguinis/mitis/oralis, Enterobacter cloacae/asburiae, Citrobacter freundii/youngae, Aeromonas hydrophila/caviae, and Burkholderia cepacia/vietnamiensis. However, Bruker Microflex LT tends to report single species and that was the reason of correct genus but wrong species results in 8 cases. This grouping style favors VITEK MS during the analysis of clinical samples because distinguishing these closely related genera is clinically irrelevant; however, it can cause certain limitations for research studies and for the analysis of environmental, food, and industrial samples.

Two Corynebacterium spp. (C. ureicelerivorans and C. appendicis) isolates confirmed with $16 \mathrm{~S}$ rDNA sequencing could only be correctly identified to the genus level by both systems. Both systems identified this isolate as $C$. pseudodiphtericum. In general, these are rare clinical isolates where molecular identification is needed mainly due to the
MALDI-TOF MS library limitations [20]. One C. ureicelerivorans and one Actinomyces naeslundii isolates, which could not be identified by VITEK MS, were identified to the genus only level by Bruker Microflex LT. Two Staphylococcus species $S$. simulans and $S$. pettenkoferi were identified to the genus level by VITEK MS; however, Bruker Microflex LT could identify both of them to the species level. On the other hand, one Myroides odoratimimus isolate could only be identified to genus level by Bruker Microflex LT, whereas it was identified to species level by VITEK MS.

VITEK MS had a relatively higher no-identification rate compared to Bruker Microflex LT in the Coryneforms and other Gram-positive bacilli group (Table 5). It has already been shown that probably due to the thick peptidoglycan layer, as it might interfere with the laser ionization, better results had been obtained with a pretreatment prior to MS run for Gram-positive bacteria [21].

Among the 3 species that could not be identified by both systems (Table 4) W. falsenii was not included in the VITEK MS library both in genus and in species level. C. glaucum was represented on the genus level but not on the species 
TABLE 5: Results summary of MALDI-TOF MS systems for the microorganisms that either were misidentified or could not be identified.

\begin{tabular}{|c|c|c|c|c|c|c|}
\hline \multirow{2}{*}{ Microorganism groups } & \multirow{2}{*}{ Number of isolates } & \multirow{2}{*}{ Species content } & \multicolumn{2}{|c|}{ Misidentification } & \multicolumn{2}{|c|}{ No-identification } \\
\hline & & & VITEK & Bruker & VITEK & Bruker \\
\hline \multicolumn{7}{|c|}{ Nonfermentatives } \\
\hline Acinetobacter baumannii & 194 & & - & - & $2(\mathrm{~F} \times 2)$ & $2(\mathrm{~F} \times 2)$ \\
\hline Aeromonas sobria & 1 & & - & - & - & $1(\mathrm{~F})$ \\
\hline Total & 356 & 16 & 2 & - & 2 & 3 \\
\hline \multicolumn{7}{|c|}{ Enterobacteriaceae } \\
\hline Kluyvera cryocrescens & 1 & & - & - & $1(\mathrm{G})$ & $1(\mathrm{G})$ \\
\hline Shigella boydii & 1 & & $1(\mathrm{~N} / \mathrm{A})$ & $1(\mathrm{~N} / \mathrm{A})$ & - & - \\
\hline Total & 309 & 23 & 1 & 1 & 1 & 1 \\
\hline \multicolumn{7}{|c|}{ Staphylococci } \\
\hline Staphylococcus epidermidis & 68 & & - & $2(\mathrm{C} \times 2)$ & - & $1(\mathrm{~F})$ \\
\hline Total & 273 & 10 & - & 2 & - & 1 \\
\hline \multicolumn{7}{|c|}{ Streptococci } \\
\hline Leuconostoc mesenteroides & 1 & & - & $1(\mathrm{~F})$ & $1(\mathrm{~F})$ & - \\
\hline Total & 29 & 11 & - & 1 & 1 & - \\
\hline \multicolumn{7}{|c|}{ Enterococci and other $\operatorname{Gr}(+)$ cocci } \\
\hline Total & 160 & 5 & - & - & - & - \\
\hline \multicolumn{7}{|c|}{ Coryneforms and other $\mathrm{Gr}(+)$ bacilli } \\
\hline Actinomyces naeslundii & 1 & & - & - & $1(\mathrm{~F})$ & - \\
\hline Corynebacterium coyleae & 1 & & $1(\mathrm{D})$ & - & - & - \\
\hline Corynebacterium glaucum & 1 & & - & - & $1(\mathrm{G})$ & $1(\mathrm{G})$ \\
\hline Corynebacterium mucifaciens & 3 & & $1(\mathrm{D})$ & - & $2(\mathrm{~F})$ & - \\
\hline Corynebacterium ureicelerivorans & 2 & & - & - & $1(\mathrm{~F})$ & - \\
\hline Total & 30 & 14 & 2 & - & 5 & 1 \\
\hline \multicolumn{7}{|c|}{ HACEK and other $\operatorname{Gr}(-)$ cocci } \\
\hline Total & 18 & 8 & - & - & - & - \\
\hline \multicolumn{7}{|c|}{ Anaerobes } \\
\hline Total & 2 & 2 & - & - & - & - \\
\hline \multicolumn{7}{|c|}{ Others } \\
\hline Wautersiella falsenii & 1 & & - & - & $1(\mathrm{G})$ & $1(\mathrm{G})$ \\
\hline Total & 4 & 4 & - & - & $1(\mathrm{G})$ & $1(\mathrm{G})$ \\
\hline Total (bacteria) & 1,181 & 93 & 5 & 4 & 10 & 7 \\
\hline \multicolumn{7}{|c|}{ Fungi } \\
\hline Aspergillus brasiliensis & 1 & & - & - & $1(\mathrm{~F})$ & - \\
\hline Total (fungi) & 160 & 14 & - & - & 1 & - \\
\hline Total (bacteria + fungi) & 1,341 & 107 & 5 & 4 & 11 & 7 \\
\hline
\end{tabular}

level in the VITEK MS library. K. cryocrescens, on the other hand, was already in the library. As we had only one isolate for the MALDI-TOF analysis, it could have been a strain specific issue. Bruker had spectra for all these three species in its library. W. falsenii and C. glaucum are represented with 2 spectra, whereas $K$. cryocrescens is represented with only 1 spectrum in Bruker BioTyper library. It is likely that this low number of spectral representation in the library was the reason for no identification. In the upcoming updates once their spectral representation is increased or included in the library, we believe both systems will perform better in the identification.

Evaluating all results together, we have observed that most of the species with incorrect and/or no identifications were not common microorganisms encountered in clinical settings and also they are either not represented in systems' libraries or represented with low number of spectra. We believe that these issues will be solved once systems' libraries are updated in the near future.

VITEK MS' species complex approach (reporting the closely related species together), which is a guaranteed attitude, increases the rate of correct identification and it is an advantage for the identifications from the routine clinical isolates. Bruker Microflex LT, however, confidently acts and reports single species, which can provide an advantage in research studies as well as in analyses of environmental, food, and industrial samples. However, consequently, both systems correctly identified $97 \%$ of 
TABLE 6: Detailed results of microorganisms that were either misidentified or could not be identified by at least one MALDI-TOF system or phenotypic identification.

\begin{tabular}{|c|c|c|c|c|c|}
\hline Correct ID & $\begin{array}{l}\text { Number of } \\
\text { isolates }\end{array}$ & $\begin{array}{l}\text { On-site phenotypic } \\
\text { identification }\end{array}$ & $\begin{array}{l}\text { Secondary phenotypic } \\
\text { identification or molecular } \\
\text { identification* (16S or } \\
\text { ITS1/2 sequencing) }\end{array}$ & VITEK & Bruker \\
\hline \multicolumn{6}{|c|}{ Nonfermentatives } \\
\hline $\begin{array}{l}\text { Achromobacter } \\
\text { xylosoxidans }\end{array}$ & 1 & $\begin{array}{l}\text { Achromobacter } \\
\text { denitrificans }\end{array}$ & $\begin{array}{l}{ }^{*} \text { Achromobacter } \\
\text { xylosoxidans }\end{array}$ & $\begin{array}{l}\text { Achromobacter denitrifi- } \\
\text { cans/xylosoxidans }\end{array}$ & $\begin{array}{l}\text { Achromobacter } \\
\text { xylosoxidans }\end{array}$ \\
\hline $\begin{array}{l}\text { Acinetobacter } \\
\text { baumannii }\end{array}$ & 1 & Cedecea lapegei & Acinetobacter baumannii & $\begin{array}{l}\text { Acinetobacter baumannii } \\
\text { complex }\end{array}$ & $\begin{array}{l}\text { Acinetobacter } \\
\text { baumannii }\end{array}$ \\
\hline $\begin{array}{l}\text { Acinetobacter } \\
\text { baumannii }\end{array}$ & 1 & Escherichia coli & $\begin{array}{l}\text { Acinetobacter baumannii } \\
\text { complex }\end{array}$ & $\begin{array}{l}\text { Acinetobacter baumannii } \\
\text { complex }\end{array}$ & $\begin{array}{l}\text { Acinetobacter } \\
\text { baumannii }\end{array}$ \\
\hline $\begin{array}{l}\text { Acinetobacter } \\
\text { baumannii }\end{array}$ & 1 & Klebsiella pneumoniae & Acinetobacter baumannii & $\begin{array}{l}\text { Acinetobacter baumannii } \\
\text { complex }\end{array}$ & $\begin{array}{l}\text { Acinetobacter } \\
\text { baumannii }\end{array}$ \\
\hline $\begin{array}{l}\text { Acinetobacter } \\
\text { baumannii }\end{array}$ & 1 & Pseudomonas aeruginosa & Acinetobacter baumannii & $\begin{array}{l}\text { Acinetobacter baumannii } \\
\text { complex }\end{array}$ & $\begin{array}{l}\text { Acinetobacter } \\
\text { baumannii }\end{array}$ \\
\hline $\begin{array}{l}\text { Acinetobacter } \\
\text { baumannii }\end{array}$ & 1 & Staphylococcus hominis & $\begin{array}{l}\text { Acinetobacter baumannii } \\
\text { complex }\end{array}$ & $\begin{array}{l}\text { Acinetobacter baumannii } \\
\text { complex }\end{array}$ & $\begin{array}{l}\text { Acinetobacter } \\
\text { baumannii }\end{array}$ \\
\hline $\begin{array}{l}\text { Acinetobacter } \\
\text { baumannii }\end{array}$ & 2 & Acinetobacter baumannii & Acinetobacter baumannii & No identification & $\begin{array}{l}\text { Acinetobacter } \\
\text { baumannii }\end{array}$ \\
\hline $\begin{array}{l}\text { Acinetobacter } \\
\text { baumannii }\end{array}$ & 2 & Acinetobacter baumannii & Acinetobacter baumannii & $\begin{array}{l}\text { Acinetobacter baumannii } \\
\text { complex }\end{array}$ & No identification \\
\hline $\begin{array}{l}\text { Acinetobacter } \\
\text { guillouiae }\end{array}$ & 1 & Acinetobacter lwoffii & ${ }^{*}$ Acinetobacter guillouiae & $\begin{array}{l}\text { Acinetobacter } \\
\text { baumannii complex }\end{array}$ & $\begin{array}{l}\text { Acinetobacter } \\
\text { guillouiae }\end{array}$ \\
\hline $\begin{array}{l}\text { Acinetobacter } \\
\text { johnsonii }\end{array}$ & 1 & Acinetobacter lwoffii & ${ }^{*}$ Acinetobacter johnsonii & Acinetobacter johnsonii & $\begin{array}{l}\text { Acinetobacter } \\
\text { johnsonii }\end{array}$ \\
\hline $\begin{array}{l}\text { Acinetobacter } \\
\text { radioresistens }\end{array}$ & 1 & Acinetobacter lwoffii & $\begin{array}{l}{ }^{*} \text { Acinetobacter } \\
\text { radioresistens }\end{array}$ & $\begin{array}{l}\text { Acinetobacter } \\
\text { radioresistens }\end{array}$ & $\begin{array}{l}\text { Acinetobacter } \\
\text { radioresistens }\end{array}$ \\
\hline $\begin{array}{l}\text { Aeromonas } \\
\text { hydrophila }\end{array}$ & 1 & Aeromonas sobria & ${ }^{*}$ Aeromonas hydrophila & $\begin{array}{l}\text { Aeromonas } \\
\text { hydrophila/caviae }\end{array}$ & $\begin{array}{l}\text { Aeromonas } \\
\text { hydrophila }\end{array}$ \\
\hline $\begin{array}{l}\text { Aeromonas } \\
\text { hydrophila }\end{array}$ & 1 & $\begin{array}{l}\text { Aeromonas } \\
\text { hydrophila/caviae }\end{array}$ & Aeromonas hydrophila & $\begin{array}{l}\text { Aeromonas } \\
\text { hydrophila/caviae }\end{array}$ & Aeromonas caviae \\
\hline Aeromonas sobria & 1 & Aeromonas sobria & ${ }^{*}$ Aeromonas sobria & $\begin{array}{l}\text { Aeromonas } \\
\text { hydrophila/caviae, sobria }\end{array}$ & No identification \\
\hline Alcaligenes faecalis & 1 & $\begin{array}{l}\text { Chromobacterium } \\
\text { violaceum }\end{array}$ & ${ }^{*}$ Alcaligenes faecalis & Alcaligenes faecalis & Alcaligenes faecalis \\
\hline $\begin{array}{l}\text { Burkholderia } \\
\text { cepacia }\end{array}$ & 2 & Burkholderia cepacia & ${ }^{*}$ Burkholderia cepacia & $\begin{array}{l}\text { Burkholderia } \\
\text { cepacia/vietnamiensis }\end{array}$ & $\begin{array}{l}\text { Burkholderia } \\
\text { cenocepacia }\end{array}$ \\
\hline $\begin{array}{l}\text { Comamonas } \\
\text { aquatica }\end{array}$ & 1 & Comamonas testosteroni & ${ }^{*}$ Comamonas aquatic & Delftia acidovorans & $\begin{array}{l}\text { Comamonas } \\
\text { aquatica }\end{array}$ \\
\hline Delftia acidovorans & 1 & No identification & Delftia acidovorans & D. acidovorans & D. acidovorans \\
\hline Delftia acidovorans & 1 & No identification & Delftia acidovorans & Delftia acidovorans & Delftia acidovorans \\
\hline $\begin{array}{l}\text { Pseudomonas } \\
\text { aeruginosa }\end{array}$ & 3 & Acinetobacter baumannii & Pseudomonas aeruginosa & Pseudomonas aeruginosa & $\begin{array}{l}\text { Pseudomonas } \\
\text { aeruginosa }\end{array}$ \\
\hline $\begin{array}{l}\text { Pseudomonas } \\
\text { aeruginosa }\end{array}$ & 1 & Enterobacter aerogenes & Pseudomonas aeruginosa & Pseudomonas aeruginosa & $\begin{array}{l}\text { Pseudomonas } \\
\text { aeruginosa }\end{array}$ \\
\hline $\begin{array}{l}\text { Pseudomonas } \\
\text { aeruginosa }\end{array}$ & 1 & Pseudomonas aeruginosa & Pseudomonas aeruginosa & $\begin{array}{l}\text { Porphyromonas } \\
\text { gingivalis }\end{array}$ & $\begin{array}{l}\text { Pseudomonas } \\
\text { aeruginosa }\end{array}$ \\
\hline $\begin{array}{l}\text { Stenotrophomonas } \\
\text { maltophilia }\end{array}$ & 1 & Pseudomonas aeruginosa & $\begin{array}{l}\text { Stenotrophomonas } \\
\text { maltophilia }\end{array}$ & $\begin{array}{l}\text { Stenotrophomonas } \\
\text { maltophilia }\end{array}$ & $\begin{array}{l}\text { Stenotrophomonas } \\
\text { maltophilia }\end{array}$ \\
\hline \multicolumn{6}{|c|}{ Enterobacteriaceae } \\
\hline $\begin{array}{l}\text { Chryseobacterium } \\
\text { indologenes }\end{array}$ & 1 & No identification & $\begin{array}{l}\text { Chryseobacterium } \\
\text { indologenes }\end{array}$ & $\begin{array}{l}\text { Chryseobacterium } \\
\text { indologenes }\end{array}$ & $\begin{array}{l}\text { Chryseobacterium } \\
\text { indologenes }\end{array}$ \\
\hline Citrobacter braakii & 1 & Citrobacter freundii & ${ }^{*}$ Citrobacter braakii & $\begin{array}{l}\text { Citrobacter } \\
\text { braakii/farmeri/freundii }\end{array}$ & Citrobacter braakii \\
\hline
\end{tabular}


TABLE 6: Continued.

\begin{tabular}{|c|c|c|c|c|c|}
\hline Correct ID & $\begin{array}{l}\text { Number of } \\
\text { isolates }\end{array}$ & $\begin{array}{l}\text { On-site phenotypic } \\
\text { identification }\end{array}$ & $\begin{array}{l}\text { Secondary phenotypic } \\
\text { identification or molecular } \\
\text { identification* ( } 16 S \text { or } \\
\text { ITS1/2 sequencing) }\end{array}$ & VITEK & Bruker \\
\hline Citrobacter freundii & 1 & No identification & Citrobacter freundii & Citrobacter freundii & Citrobacter freundii \\
\hline Citrobacter sedlakii & 1 & Citrobacter amalonaticus & ${ }^{*}$ Citrobacter sedlakii & Citrobacter sedlakii & Citrobacter sedlakii \\
\hline $\begin{array}{l}\text { Citrobacter } \\
\text { youngae }\end{array}$ & 1 & No identification & Citrobacter youngae & $\begin{array}{l}\text { Citrobacter } \\
\text { freundii/youngae }\end{array}$ & $\begin{array}{l}\text { Citrobacter } \\
\text { youngae }\end{array}$ \\
\hline $\begin{array}{l}\text { Citrobacter } \\
\text { youngae }\end{array}$ & 1 & Citrobacter youngae & ${ }^{*}$ Citrobacter youngae & $\begin{array}{l}\text { Citrobacter } \\
\text { freundii/youngae }\end{array}$ & $\begin{array}{l}\text { Citrobacter } \\
\text { freundii }\end{array}$ \\
\hline $\begin{array}{l}\text { Enterobacter } \\
\text { asburiae }\end{array}$ & 1 & Escherichia coli & $\begin{array}{l}\text { Enterobacter cloacae } \\
\text { complex }\end{array}$ & $\begin{array}{l}\text { Enterobacter } \\
\text { cloacae/asburiae }\end{array}$ & $\begin{array}{l}\text { Enterobacter } \\
\text { asburiae }\end{array}$ \\
\hline $\begin{array}{l}\text { Enterobacter } \\
\text { asburiae }\end{array}$ & 1 & $\begin{array}{l}\text { Enterobacter cloacae } \\
\text { complex }\end{array}$ & ${ }^{*}$ Enterobacter asburiae & $\begin{array}{l}\text { Enterobacter } \\
\text { cloacae/asburiae }\end{array}$ & $\begin{array}{l}\text { Enterobacter } \\
\text { cloacae }\end{array}$ \\
\hline $\begin{array}{l}\text { Enterobacter } \\
\text { cancerogenous }\end{array}$ & 1 & Enterobacter aerogenes & Enterobacter cancerogenous & $\begin{array}{l}\text { Enterobacter } \\
\text { cancerogenous }\end{array}$ & $\begin{array}{l}\text { Enterobacter } \\
\text { cancerogenous }\end{array}$ \\
\hline $\begin{array}{l}\text { Enterobacter } \\
\text { cloacae }\end{array}$ & 1 & Enterobacter cancerogenus & $\begin{array}{l}\text { Enterobacter cloacae } \\
\text { complex }\end{array}$ & $\begin{array}{l}\text { Enterobacter } \\
\text { cloacae/asburiae }\end{array}$ & $\begin{array}{l}\text { Enterobacter } \\
\text { cloacae }\end{array}$ \\
\hline $\begin{array}{l}\text { Enterobacter } \\
\text { cloacae }\end{array}$ & 1 & No identification & $\begin{array}{l}\text { Enterobacter cloacae } \\
\text { complex }\end{array}$ & $\begin{array}{l}\text { Enterobacter } \\
\text { cloacae/asburiae }\end{array}$ & $\begin{array}{l}\text { Enterobacter } \\
\text { cloacae }\end{array}$ \\
\hline $\begin{array}{l}\text { Enterobacter } \\
\text { cloacae }\end{array}$ & 1 & No identification & Enterobacter cloacae & $\begin{array}{l}\text { Enterobacter } \\
\text { cloacae/asburiae }\end{array}$ & $\begin{array}{l}\text { Enterobacter } \\
\text { cloacae }\end{array}$ \\
\hline $\begin{array}{l}\text { Enterobacter } \\
\text { cloacae }\end{array}$ & 1 & Enterobacter cloacae & ${ }^{*}$ Enterobacter cloacae & $\begin{array}{l}\text { Enterobacter } \\
\text { cloacae/asburiae }\end{array}$ & $\begin{array}{l}\text { Enterobacter } \\
\text { asburiae }\end{array}$ \\
\hline $\begin{array}{l}\text { Enterobacter } \\
\text { cloacae }\end{array}$ & 1 & Enterobacter cloacae & Enterobacter cloacae & $\begin{array}{l}\text { Enterobacter } \\
\text { cloacae/asburiae }\end{array}$ & $\begin{array}{l}\text { Enterobacter } \\
\text { asburiae }\end{array}$ \\
\hline $\begin{array}{l}\text { Enterobacter } \\
\text { cloacae }\end{array}$ & 1 & No identification & Enterobacter cloacae & $\begin{array}{l}\text { Enterobacter } \\
\text { cloacae/asburiae }\end{array}$ & $\begin{array}{l}\text { Enterobacter } \\
\text { cloacae }\end{array}$ \\
\hline Klebsiella oxytoca & 1 & Escherichia coli & Klebsiella oxytoca & Klebsiella oxytoca & Klebsiella oxytoca \\
\hline $\begin{array}{l}\text { Klebsiella } \\
\text { pneumoniae }\end{array}$ & 1 & Acinetobacter baumannii & Klebsiella pneumonia & Klebsiella pneumoniae & $\begin{array}{l}\text { Klebsiella } \\
\text { pneumoniae }\end{array}$ \\
\hline $\begin{array}{l}\text { Klebsiella } \\
\text { pneumoniae }\end{array}$ & 1 & Enterobacter aerogenes & Klebsiella pneumonia & Klebsiella pneumoniae & $\begin{array}{l}\text { Klebsiella } \\
\text { pneumoniae }\end{array}$ \\
\hline $\begin{array}{l}\text { Klebsiella } \\
\text { pneumoniae }\end{array}$ & 1 & Enterobacter aerogenes & ${ }^{*}$ Klebsiella pneumoniae & Klebsiella pneumoniae & $\begin{array}{l}\text { Klebsiella } \\
\text { pneumoniae }\end{array}$ \\
\hline $\begin{array}{l}\text { Klebsiella } \\
\text { pneumoniae }\end{array}$ & 1 & Escherichia coli & Klebsiella pneumonia & Klebsiella pneumoniae & $\begin{array}{l}\text { Klebsiella } \\
\text { pneumoniae }\end{array}$ \\
\hline $\begin{array}{l}\text { Kluyvera } \\
\text { cryocrescens }\end{array}$ & 1 & Raoultella planticola & ${ }^{*}$ Kluyvera cryocrescens & No identification & No identification \\
\hline Proteus mirabilis & 1 & $\begin{array}{l}\text { Stenotrophomonas } \\
\text { maltophilia }\end{array}$ & Proteus mirabilis & Proteus mirabilis & Proteus mirabilis \\
\hline $\begin{array}{l}\text { Raoultella } \\
\text { ornithinolytica }\end{array}$ & 1 & No identification & ${ }^{*}$ Raoultella ornithinolytica & $\begin{array}{l}\text { Raoultella } \\
\text { ornithinolytica/planticola }\end{array}$ & $\begin{array}{l}\text { Raoultella } \\
\text { ornithinolytica }\end{array}$ \\
\hline Shigella boydii & 1 & Shigella boydii & Shigella boydii & Escherichia coli & Escherichia coli \\
\hline \multicolumn{6}{|c|}{ Staphylococci } \\
\hline $\begin{array}{l}\text { Staphylococcus } \\
\text { aureus }\end{array}$ & 1 & Acinetobacter baumannii & Staphylococcus aureus & Staphylococcus aureus & $\begin{array}{l}\text { Staphylococcus } \\
\text { aureus }\end{array}$ \\
\hline $\begin{array}{l}\text { Staphylococcus } \\
\text { hominis }\end{array}$ & 1 & Acinetobacter baumannii & Staphylococcus hominis & Staphylococcus hominis & $\begin{array}{l}\text { Staphylococcus } \\
\text { hominis }\end{array}$ \\
\hline $\begin{array}{l}\text { Staphylococcus } \\
\text { epidermidis }\end{array}$ & 1 & Enterococcus faecium & Staphylococcus epidermidis & $\begin{array}{l}\text { Staphylococcus } \\
\text { epidermidis }\end{array}$ & $\begin{array}{l}\text { Staphylococcus } \\
\text { epidermidis }\end{array}$ \\
\hline $\begin{array}{l}\text { Staphylococcus } \\
\text { simulans }\end{array}$ & 1 & Granulicatella elegans & *Staphylococcus simulans & $\begin{array}{l}\text { Staphylococcus } \\
\text { haemolyticus }\end{array}$ & $\begin{array}{l}\text { Staphylococcus } \\
\text { simulans }\end{array}$ \\
\hline
\end{tabular}


TABle 6: Continued.

\begin{tabular}{|c|c|c|c|c|c|}
\hline Correct ID & $\begin{array}{l}\text { Number of } \\
\text { isolates }\end{array}$ & $\begin{array}{l}\text { On-site phenotypic } \\
\text { identification }\end{array}$ & $\begin{array}{l}\text { Secondary phenotypic } \\
\text { identification or molecular } \\
\text { identification* (16S or } \\
\text { ITS1/2 sequencing) }\end{array}$ & VITEK & Bruker \\
\hline $\begin{array}{l}\text { Staphylococcus } \\
\text { haemolyticus }\end{array}$ & 1 & Staphylococcus aureus & $\begin{array}{l}\text { Staphylococcus } \\
\text { haemolyticus }\end{array}$ & $\begin{array}{l}\text { Staphylococcus } \\
\text { haemolyticus }\end{array}$ & $\begin{array}{l}\text { Staphylococcus } \\
\text { haemolyticus }\end{array}$ \\
\hline $\begin{array}{l}\text { Staphylococcus } \\
\text { pettenkoferi }\end{array}$ & 1 & Staphylococcus auricularis & $\begin{array}{l}{ }^{*} \text { Staphylococcus } \\
\text { pettenkoferi }\end{array}$ & $\begin{array}{l}\text { Staphylococcus } \\
\text { auricularis/capitis }\end{array}$ & $\begin{array}{l}\text { Staphylococcus } \\
\text { pettenkoferi }\end{array}$ \\
\hline $\begin{array}{l}\text { Staphylococcus } \\
\text { hominis }\end{array}$ & 1 & $\begin{array}{l}\text { Staphylococcus } \\
\text { epidermidis }\end{array}$ & Staphylococcus hominis & Staphylococcus hominis & $\begin{array}{l}\text { Staphylococcus } \\
\text { hominis }\end{array}$ \\
\hline $\begin{array}{l}\text { Staphylococcus } \\
\text { aureus }\end{array}$ & 1 & $\begin{array}{l}\text { Staphylococcus } \\
\text { haemolyticus }\end{array}$ & Staphylococcus aureus & Staphylococcus aureus & $\begin{array}{l}\text { Staphylococcus } \\
\text { aureus }\end{array}$ \\
\hline $\begin{array}{l}\text { Staphylococcus } \\
\text { capitis }\end{array}$ & 1 & $\begin{array}{l}\text { Staphylococcus } \\
\text { haemolyticus }\end{array}$ & Staphylococcus capitis & Staphylococcus capitis & $\begin{array}{l}\text { Staphylococcus } \\
\text { capitis }\end{array}$ \\
\hline $\begin{array}{l}\text { Staphylococcus } \\
\text { aureus }\end{array}$ & 1 & Staphylococcus hominis & Staphylococcus aureus & Staphylococcus aureus & $\begin{array}{l}\text { Staphylococcus } \\
\text { aureus }\end{array}$ \\
\hline $\begin{array}{l}\text { Staphylococcus } \\
\text { epidermidis }\end{array}$ & 1 & Staphylococcus hominis & Staphylococcus epidermidis & $\begin{array}{l}\text { Staphylococcus } \\
\text { epidermidis }\end{array}$ & $\begin{array}{l}\text { Staphylococcus } \\
\text { epidermidis }\end{array}$ \\
\hline $\begin{array}{l}\text { Staphylococcus } \\
\text { epidermidis }\end{array}$ & 1 & Staphylococcus lentus & Staphylococcus epidermidis & $\begin{array}{l}\text { Staphylococcus } \\
\text { epidermidis }\end{array}$ & $\begin{array}{l}\text { Staphylococcus } \\
\text { epidermidis }\end{array}$ \\
\hline $\begin{array}{l}\text { Staphylococcus } \\
\text { hominis }\end{array}$ & 1 & $\begin{array}{l}\text { Staphylococcus } \\
\text { saprophyticus }\end{array}$ & Staphylococcus hominis & Staphylococcus hominis & $\begin{array}{l}\text { Staphylococcus } \\
\text { hominis }\end{array}$ \\
\hline $\begin{array}{l}\text { Staphylococcus } \\
\text { hominis }\end{array}$ & 1 & Staphylococcus warneri & ${ }^{*}$ Staphylococcus hominis & Staphylococcus hominis & $\begin{array}{l}\text { Staphylococcus } \\
\text { hominis }\end{array}$ \\
\hline $\begin{array}{l}\text { Staphylococcus } \\
\text { hominis }\end{array}$ & 2 & Staphylococcus warneri & ${ }^{*}$ Staphylococcus hominis & Staphylococcus hominis & $\begin{array}{l}\text { Staphylococcus } \\
\text { hominis }\end{array}$ \\
\hline $\begin{array}{l}\text { Staphylococcus } \\
\text { haemolyticus }\end{array}$ & 1 & Staphylococcus warneri & $\begin{array}{l}\text { Staphylococcus } \\
\text { haemolyticus }\end{array}$ & $\begin{array}{l}\text { Staphylococcus } \\
\text { haemolyticus }\end{array}$ & $\begin{array}{l}\text { Staphylococcus } \\
\text { haemolyticus }\end{array}$ \\
\hline $\begin{array}{l}\text { Staphylococcus } \\
\text { epidermidis }\end{array}$ & 1 & Staphylococcus epidermidis & Staphylococcus epidermidis & $\begin{array}{l}\text { Staphylococcus } \\
\text { epidermidis }\end{array}$ & Bacillus pumilus \\
\hline $\begin{array}{l}\text { Staphylococcus } \\
\text { epidermidis }\end{array}$ & 1 & Staphylococcus epidermidis & Staphylococcus epidermidis & $\begin{array}{l}\text { Staphylococcus } \\
\text { epidermidis }\end{array}$ & $\begin{array}{l}\text { Dermobacter } \\
\text { hominis }\end{array}$ \\
\hline $\begin{array}{l}\text { Staphylococcus } \\
\text { aureus }\end{array}$ & 1 & No identification & Staphylococcus aureus & Staphylococcus aureus & $\begin{array}{l}\text { Staphylococcus } \\
\text { aureus }\end{array}$ \\
\hline $\begin{array}{l}\text { Staphylococcus } \\
\text { lugdunensis }\end{array}$ & 1 & No identification & Staphylococcus lugdunensis & $\begin{array}{l}\text { Staphylococcus } \\
\text { lugdunensis }\end{array}$ & $\begin{array}{l}\text { Staphylococcus } \\
\text { lugdunensis }\end{array}$ \\
\hline $\begin{array}{l}\text { Staphylococcus } \\
\text { epidermidis }\end{array}$ & 1 & Staphylococcus epidermidis & Staphylococcus epidermidis & $\begin{array}{l}\text { Staphylococcus } \\
\text { epidermidis }\end{array}$ & No identification \\
\hline & & & Streptococci & & \\
\hline $\begin{array}{l}\text { Leuconostoc } \\
\text { mesenteroides }\end{array}$ & 1 & Staphylococcus capitis & ${ }^{*}$ Leuconostoc mesenteroides & No identification & $\begin{array}{l}\text { Staphylococcus } \\
\text { pettenkoferi }\end{array}$ \\
\hline $\begin{array}{l}\text { Streptococcus } \\
\text { agalactiae }\end{array}$ & 3 & No identification & Streptococcus agalactiae & Streptococcus agalactiae & $\begin{array}{l}\text { Streptococcus } \\
\text { agalactiae }\end{array}$ \\
\hline $\begin{array}{l}\text { Streptococcus } \\
\text { dysgalactiae }\end{array}$ & 1 & No identification & ${ }^{*}$ Streptococcus dysgalactiae & $\begin{array}{l}\text { Streptococcus } \\
\text { dysgalactiae }\end{array}$ & $\begin{array}{l}\text { Streptococcus } \\
\text { dysgalactiae }\end{array}$ \\
\hline Streptococcus mitis & 1 & Streptococcus mitis & Streptococcus mitis & $\begin{array}{l}\text { Streptococcus parasan- } \\
\text { guinis/mitis/oralis }\end{array}$ & $\begin{array}{l}\text { Streptococcus } \\
\text { pneumoniae }\end{array}$ \\
\hline $\begin{array}{l}\text { Streptococcus } \\
\text { salivarius }\end{array}$ & 1 & Streptococcus lentus & Streptococcus salivarius & Streptococcus salivarius & $\begin{array}{l}\text { Streptococcus } \\
\text { salivarius }\end{array}$ \\
\hline \multicolumn{6}{|c|}{ Enterococci \& other $\operatorname{Gr}(+)$ cocci } \\
\hline $\begin{array}{l}\text { Enterococcus } \\
\text { faecalis }\end{array}$ & 1 & Escherichia coli & Enterococcus faecalis & Enterococcus faecalis & $\begin{array}{l}\text { Enterococcus } \\
\text { faecalis }\end{array}$ \\
\hline $\begin{array}{l}\text { Enterococcus } \\
\text { faecium }\end{array}$ & 1 & Enterococcus faecalis & Enterococcus faecium & Enterococcus faecium & $\begin{array}{l}\text { Enterococcus } \\
\text { faecium }\end{array}$ \\
\hline
\end{tabular}


TABle 6: Continued.

\begin{tabular}{|c|c|c|c|c|c|}
\hline Correct ID & $\begin{array}{c}\text { Number of } \\
\text { isolates }\end{array}$ & $\begin{array}{l}\text { On-site phenotypic } \\
\text { identification }\end{array}$ & $\begin{array}{l}\text { Secondary phenotypic } \\
\text { identification or molecular } \\
\text { identification* (16S or } \\
\text { ITS1/2 sequencing) }\end{array}$ & VITEK & Bruker \\
\hline $\begin{array}{l}\text { Enterococcus } \\
\text { faecalis }\end{array}$ & 2 & Enterococcus faecium & Enterococcus faecalis & Enterococcus faecalis & $\begin{array}{l}\text { Enterococcus } \\
\text { faecalis }\end{array}$ \\
\hline $\begin{array}{l}\text { Enterococcus } \\
\text { gallinarum }\end{array}$ & 1 & Enterococcus faecium & ${ }^{*}$ Enterococcus gallinarum & Enterococcus gallinarum & $\begin{array}{l}\text { Enterococcus } \\
\text { gallinarum }\end{array}$ \\
\hline $\begin{array}{l}\text { Enterococcus } \\
\text { faecium }\end{array}$ & 2 & Enterococcus gallinarum & Enterococcus faecium & Enterococcus faecium & $\begin{array}{l}\text { Enterococcus } \\
\text { faecium }\end{array}$ \\
\hline $\begin{array}{l}\text { Enterococcus } \\
\text { faecalis }\end{array}$ & 1 & Serratia fonticola & Enterococcus faecalis & Enterococcus faecalis & $\begin{array}{l}\text { Enterococcus } \\
\text { faecalis }\end{array}$ \\
\hline $\begin{array}{l}\text { Enterococcus } \\
\text { faecalis }\end{array}$ & 1 & Staphylococcus hominis & Enterococcus faecalis & Enterococcus faecalis & $\begin{array}{l}\text { Enterococcus } \\
\text { faecalis }\end{array}$ \\
\hline \multicolumn{6}{|c|}{ Coryneforms \& other $\mathrm{Gr}(+)$ bacilli } \\
\hline $\begin{array}{l}\text { Corynebacterium } \\
\text { striatum }\end{array}$ & 1 & Actinomyces spp. & Corynebacterium striatum & $\begin{array}{l}\text { Corynebacterium } \\
\text { striatum }\end{array}$ & $\begin{array}{l}\text { Corynebacterium } \\
\text { striatum }\end{array}$ \\
\hline $\begin{array}{l}\text { Corynebacterium } \\
\text { urealyticum }\end{array}$ & 1 & Brucella spp. & $\begin{array}{l}\text { Corynebacterium } \\
\text { urealyticum }\end{array}$ & $\begin{array}{l}\text { Corynebacterium } \\
\text { urealyticum }\end{array}$ & $\begin{array}{l}\text { Corynebacterium } \\
\text { urealyticum }\end{array}$ \\
\hline $\begin{array}{l}\text { Corynebacterium } \\
\text { appendicis }\end{array}$ & 1 & Corynebacterium jeikeium & $\begin{array}{l}{ }^{*} \text { Corynebacterium } \\
\text { appendicis }\end{array}$ & $\begin{array}{l}\text { Corynebacterium } \\
\text { pseudodiphtericum }\end{array}$ & $\begin{array}{l}\text { Corynebacterium } \\
\text { pseudodiphter- } \\
\text { icum }\end{array}$ \\
\hline $\begin{array}{l}\text { Corynebacterium } \\
\text { ureicelerivorans }\end{array}$ & 1 & Corynebacterium jeikeium & $\begin{array}{l}{ }^{*} \text { Corynebacterium } \\
\text { ureicelerivorans }\end{array}$ & $\begin{array}{l}\text { Corynebacterium } \\
\text { afermentans }\end{array}$ & $\begin{array}{l}\text { Corynebacterium } \\
\text { afermentans }\end{array}$ \\
\hline $\begin{array}{l}\text { Corynebacterium } \\
\text { mucifaciens }\end{array}$ & 2 & Corynebacterium jeikeium & $\begin{array}{l}{ }^{*} \text { Corynebacterium } \\
\text { mucifaciens }\end{array}$ & No identification & $\begin{array}{l}\text { Corynebacterium } \\
\text { mucifaciens }\end{array}$ \\
\hline $\begin{array}{l}\text { Corynebacterium } \\
\text { ureicelerivorans }\end{array}$ & 1 & Corynebacterium jeikeium & $\begin{array}{l}{ }^{*} \text { Corynebacterium } \\
\text { ureicelerivorans }\end{array}$ & No identification & $\begin{array}{l}\text { Corynebacterium } \\
\text { coyleae }\end{array}$ \\
\hline $\begin{array}{l}\text { Corynebacterium } \\
\text { glaucum }\end{array}$ & 1 & Corynebacterium jeikeium & ${ }^{*}$ Corynebacterium glaucum & No identification & No identification \\
\hline $\begin{array}{l}\text { Corynebacterium } \\
\text { mucifaciens }\end{array}$ & 1 & Clostridium spp. & $\begin{array}{l}{ }^{*} \text { Corynebacterium } \\
\text { mucifaciens }\end{array}$ & Rhizobium radiobacter & $\begin{array}{l}\text { Corynebacterium } \\
\text { mucifaciens }\end{array}$ \\
\hline $\begin{array}{l}\text { Corynebacterium } \\
\text { coyleae }\end{array}$ & 1 & $\begin{array}{l}\text { Dermococcus/Kytococcus/ } \\
\text { Micrococcus }\end{array}$ & ${ }^{*}$ Corynebacterium coyleae & Arthrobacter cumminsii & $\begin{array}{l}\text { Corynebacterium } \\
\text { coyleae }\end{array}$ \\
\hline $\begin{array}{l}\text { Lactobacillus } \\
\text { paracasei }\end{array}$ & 1 & Pediococcus pentosaceus & ${ }^{*}$ Lactobacillus paracasei & $\begin{array}{l}\text { Lactobacillus } \\
\text { casei/paracasei }\end{array}$ & $\begin{array}{l}\text { Lactobacillus } \\
\text { paracasei }\end{array}$ \\
\hline $\begin{array}{l}\text { Corynebacterium } \\
\text { striatum }\end{array}$ & 1 & Propionibacterium acnes & Corynebacterium striatum & $\begin{array}{l}\text { Corynebacterium } \\
\text { striatum }\end{array}$ & $\begin{array}{l}\text { Corynebacterium } \\
\text { striatum }\end{array}$ \\
\hline Bacillus simplex & 1 & $\begin{array}{l}\text { Sphingomonas } \\
\text { paucimobilis }\end{array}$ & Bacillus simplex & Bacillus simplex & Bacillus simplex \\
\hline $\begin{array}{l}\text { Corynebacterium } \\
\text { amycolatum }\end{array}$ & 1 & Bacillus spp. & $\begin{array}{l}\text { Corynebacterium } \\
\text { amycolatum }\end{array}$ & $\begin{array}{l}\text { Corynebacterium } \\
\text { amycolatum/xerosis }\end{array}$ & $\begin{array}{l}\text { Corynebacterium } \\
\text { amycolatum }\end{array}$ \\
\hline $\begin{array}{l}\text { Corynebacterium } \\
\text { jeikeium }\end{array}$ & 2 & Bacillus spp. & Corynebacterium jeikeium & $\begin{array}{l}\text { Corynebacterium } \\
\text { jeikeium }\end{array}$ & $\begin{array}{l}\text { Corynebacterium } \\
\text { jeikeium }\end{array}$ \\
\hline $\begin{array}{l}\text { Corynebacterium } \\
\text { striatum }\end{array}$ & 2 & Bacillus spp. & Corynebacterium striatum & $\begin{array}{l}\text { Corynebacterium } \\
\text { striatum }\end{array}$ & $\begin{array}{l}\text { Corynebacterium } \\
\text { striatum }\end{array}$ \\
\hline $\begin{array}{l}\text { Actinomyces } \\
\text { naeslundii }\end{array}$ & 1 & Actinomyces naeslundii & ${ }^{*}$ Actinomyces naeslundii & No identification & Actinomyces spp. \\
\hline \multicolumn{6}{|c|}{ HACEK \& other Gr(-) cocci } \\
\hline $\begin{array}{l}\text { Moraxella } \\
\text { catarrhalis }\end{array}$ & 1 & $\begin{array}{l}\text { Arcanobacterium } \\
\text { hemoliticum }\end{array}$ & Moraxella catarrhalis & Moraxella catarrhalis & $\begin{array}{l}\text { Moraxella } \\
\text { catarrhalis }\end{array}$ \\
\hline $\begin{array}{l}\text { Haemophilus } \\
\text { influenzae }\end{array}$ & 1 & Bacillus spp. & Haemophilus influenzae & Haemophilus influenzae & $\begin{array}{l}\text { Haemophilus } \\
\text { influenzae }\end{array}$ \\
\hline
\end{tabular}


TABLE 6: Continued.

\begin{tabular}{|c|c|c|c|c|c|}
\hline Correct ID & $\begin{array}{l}\text { Number of } \\
\text { isolates }\end{array}$ & $\begin{array}{l}\text { On-site phenotypic } \\
\text { identification }\end{array}$ & $\begin{array}{l}\text { Secondary phenotypic } \\
\text { identification or molecular } \\
\text { identification* (16S or } \\
\text { ITS1/2 sequencing) }\end{array}$ & VITEK & Bruker \\
\hline $\begin{array}{l}\text { Pasteurella } \\
\text { multocida }\end{array}$ & 1 & Bacillus spp. & ${ }^{*}$ Pasteurella multocida & Pasteurella multocida & $\begin{array}{l}\text { Pasteurella } \\
\text { multocida }\end{array}$ \\
\hline \multicolumn{6}{|c|}{ Others } \\
\hline $\begin{array}{l}\text { Bergeyella } \\
\text { zoohelcum }\end{array}$ & 1 & No identification & ${ }^{*}$ Bergeyella zoohelcum & Bergeyella zoohelcum & $\begin{array}{l}\text { Bergeyella } \\
\text { zoohelcum }\end{array}$ \\
\hline $\begin{array}{l}\text { Wautersiella } \\
\text { falsenii }\end{array}$ & 1 & Weeksella virosa & ${ }^{*}$ Wautersiella falsenii & No identification & No identification \\
\hline $\begin{array}{l}\text { Myroides } \\
\text { odoratimimus }\end{array}$ & 1 & Myroides spp. & ${ }^{*}$ Myroides odoratimimus & Myroides odoratimimus & Myroides spp. \\
\hline \multicolumn{6}{|c|}{ Fungi } \\
\hline Candida glabrata & 2 & Candida albicans & Candida glabrata & Candida glabrata & Candida glabrata \\
\hline Candida albicans & 1 & Candida famata & Candida albicans & Candida albicans & Candida albicans \\
\hline Candida tropicalis & 1 & Candida famata & Candida tropicalis & $\begin{array}{l}\text { Candida } \\
\text { tropicalis/glabrata }\end{array}$ & Candida tropicalis \\
\hline Candida tropicalis & 1 & Candida famata & ${ }^{*}$ Candida tropicalis & Candida tropicalis & Candida tropicalis \\
\hline Candida albicans & 2 & Candida glabrata & Candida albicans & Candida albicans & Candida albicans \\
\hline Candida glabrata & 1 & Candida lusitaniae & Candida glabrata & Candida glabrata & Candida glabrata \\
\hline Candida tropicalis & 2 & Candida parapsilosis & Candida tropicalis & Candida tropicalis & Candida tropicalis \\
\hline Candida glabrata & 1 & Candida rugose & Candida glabrata & Candida glabrata & Candida glabrata \\
\hline Candida kefyr & 1 & Candida sphaerica & Candida kefyr & Candida kefyr & Candida kefyr \\
\hline $\begin{array}{l}\text { Candida } \\
\text { orthopsilosis }\end{array}$ & 1 & Candida tropicalis & ${ }^{*}$ Candida orthopsilosis & Candida parapsilosis & $\begin{array}{l}\text { Candida } \\
\text { orthopsilosis }\end{array}$ \\
\hline $\begin{array}{l}\text { Candida } \\
\text { parapsilosis }\end{array}$ & 2 & Candida spp. & ${ }^{*}$ Candida parapsilosis & Candida parapsilosis & $\begin{array}{l}\text { Candida } \\
\text { parapsilosis }\end{array}$ \\
\hline $\begin{array}{l}\text { Candida } \\
\text { orthopsilosis }\end{array}$ & 1 & Candida spp. & ${ }^{*}$ Candida orthopsilosis & Candida parapsilosis & $\begin{array}{l}\text { Candida } \\
\text { orthopsilosis }\end{array}$ \\
\hline $\begin{array}{l}\text { Meyerozyma } \\
\text { caribbica }\end{array}$ & 1 & Candida spp. & ${ }^{*}$ Meyerozyma caribbica & Candida guilliermondii & $\begin{array}{l}\text { Candida } \\
\text { guilliermondii }\end{array}$ \\
\hline Candida albicans & 1 & Stephanoascus ciferrii & Candida albicans & Candida albicans & Candida albicans \\
\hline Candida krusei & 1 & No identification & Candida krusei & Candida krusei & Candida krusei \\
\hline Candida albicans & 1 & Candida albicans & Candida albicans & Candida albicans & Candida tropicalis \\
\hline Candida albicans & 1 & Candida albicans & Candida albicans & Candida albicans & Candida glabrata \\
\hline $\begin{array}{l}\text { Candida } \\
\text { parapsilosis }\end{array}$ & 1 & Candida parapsilosis & ${ }^{*}$ Candida parapsilosis & Candida parapsilosis & $\begin{array}{l}\text { Candida } \\
\text { orthopsilosis }\end{array}$ \\
\hline $\begin{array}{l}\text { Aspergillus } \\
\text { brasiliensis }\end{array}$ & 1 & Aspergillus brasiliensis & Aspergillus brasiliensis & No identification & $\begin{array}{l}\text { Aspergillus } \\
\text { brasiliensis }\end{array}$ \\
\hline
\end{tabular}

${ }^{*}$ Molecular identification (16S or ITS1/2 sequencing).

routine clinical isolates making them reliable tools for clinical microbiology laboratories.

Comparing final confirmed identifications, MALDI-TOF MS systems showed a better identification accuracy compared to phenotypic identification. In addition to a better accuracy, a faster workflow and considerable lower cost provide clinical laboratories with a better identification tool $[22,23]$.

\section{Conflict of Interests}

The authors declare that they have no conflict of interests.

\section{References}

[1] A. Croxatto, G. Prod'hom, and G. Greub, "Applications of MALDI-TOF mass spectrometry in clinical diagnostic microbiology," FEMS Microbiology Reviews, vol. 36, no. 2, pp. 380-407, 2012.

[2] M. A. Claydon, S. N. Davey, V. Edwards-Jones, and D. B. Gordon, "The rapid identification of intact microorganisms using mass spectrometry," Nature Biotechnology, vol. 14, no. 11, pp. 1584-1586, 1996.

[3] R. D. Holland, J. G. Wilkes, F. Rafii et al., "Rapid identification of intact whole bacteria based on spectral patterns using matrixassisted laser desorption/ionization with time-of- flight mass 
spectrometry," Rapid Communications in Mass Spectrometry, vol. 10, no. 10, pp. 1227-1232, 1996.

[4] T.-Y. Li, B.-H. Liu, and Y.-C. Chen, "Characterization of Aspergillus spores by matrix-assisted laser desorption/ionization time-of-flight mass spectrometry," Rapid Communications in Mass Spectrometry, vol. 14, no. 24, pp. 2393-2400, 2000.

[5] K. J. Welham, M. A. Domin, K. Johnson, L. Jones, and D. S. Ashton, "Characterization of fungal spores by laser desorption/ ionization time-of-flight mass spectrometry," Rapid Communications in Mass Spectrometry, vol. 14, no. 5, pp. 307-310, 2000.

[6] P. Seng, M. Drancourt, F. Gouriet et al., "Ongoing revolution in bacteriology: routine identification of bacteria by matrixassisted laser desorption ionization time-of-flight mass spectrometry," Clinical Infectious Diseases, vol. 49, no. 4, pp. 543-551, 2009.

[7] D. Parisi, M. Magliulo, P. Nanni, M. Casale, M. Forina, and A. Roda, "Analysis and classification of bacteria by matrix-assisted laser desorption/ionization time-of-flight mass spectrometry and a chemometric approach," Analytical and Bioanalytical Chemistry, vol. 391, no. 6, pp. 2127-2134, 2008.

[8] G. Yaman, I. Akyar, and S. Can, "Evaluation of the MALDI TOFMS method for identification of Candida strains isolated from blood cultures," Diagnostic Microbiology and Infectious Disease, vol. 73, no. 1, pp. 65-67, 2012.

[9] J. Qian, J. E. Cutler, R. B. Cole, and Y. Cai, "MALDI-TOF mass signatures for differentiation of yeast species, strain grouping and monitoring of morphogenesis markers," Analytical and Bioanalytical Chemistry, vol. 392, no. 3, pp. 439-449, 2008.

[10] M.-C. Wang, W.-H. Lin, J.-J. Yan et al., "Early identification of microorganisms in blood culture prior to the detection of a positive signal in the BACTEC FX system using matrix-assisted laser desorption/ionization-time of flight mass spectrometry," Journal of Microbiology, Immunology and Infection, vol. 48, no. 4, pp. 419-424, 2015.

[11] E. Bessède, M. Angla-gre, Y. Delagarde, S. Sep Hieng, A. Ménard, and F. Mégraud, "Matrix-assisted laser-desorption/ ionization BIOTYPER: experience in the routine of a University hospital," Clinical Microbiology and Infection, vol. 17, no. 4, pp. 533-538, 2011.

[12] A. Alanio, J.-L. Beretti, B. Dauphin et al., "Matrix-assisted laser desorption ionization time-of-flight mass spectrometry for fast and accurate identification of clinically relevant Aspergillus species," Clinical Microbiology and Infection, vol. 17, no. 5, pp. 750-755, 2011.

[13] M. L. Demarco and C.-A. D. Burnham, "Diafiltration MALDITOF mass spectrometry method for culture-independent detection and identification of pathogens directly from urine specimens," American Journal of Clinical Pathology, vol. 141, no. 2, pp. 204-212, 2014.

[14] M. Drancourt, "Detection of microorganisms in blood specimens using matrix-assisted laser desorption ionization time-offlight mass spectrometry: a review," Clinical Microbiology and Infection, vol. 16, no. 11, pp. 1620-1625, 2010.

[15] Y. Hoyos-Mallecot, C. Riazzo, C. Miranda-Casas, M. RojoMartín, J. Gutiérrez-Fernández, and J. Navarro-Marí, "Rapid detection and identification of strains carrying carbapenemases directly from positive blood cultures using MALDI-TOF MS," Journal of Microbiological Methods, vol. 105, pp. 98-101, 2014.

[16] A. Suau, R. Bonnet, M. Sutren et al., "Direct analysis of genes encoding 16S rRNA from complex communities reveals many novel molecular species within the human gut," Applied and Environmental Microbiology, vol. 65, no. 11, pp. 4799-4807, 1999.
[17] W. G. Weisburg, S. M. Barns, D. A. Pelletier, and D. J. Lane, "16S ribosomal DNA amplification for phylogenetic study," Journal of Bacteriology, vol. 173, no. 2, pp. 697-703, 1991.

[18] M. Korabecna, "The variability in the fungal ribosomal DNA (ITS1, ITS2, and 5.8 S rRNA gene): its biological meaning and application in medical mycology," in Communicating Current Research and Educational Topics and Trends in Applied Microbiology, pp. 783-787, Formatex, 2007.

[19] A. Wieser, L. Schneider, J. Jung, and S. Schubert, "MALDI-TOF MS in microbiological diagnostics-identification of microorganisms and beyond (mini review)," Applied Microbiology and Biotechnology, vol. 93, no. 3, pp. 965-974, 2012.

[20] P. Seng, C. Abat, J. M. Rolain et al., "Identification of rare pathogenic bacteria in a clinical microbiology laboratory: impact of matrix-assisted laser desorption ionization-time of flight mass spectrometry," Journal of Clinical Microbiology, vol. 51, no. 7, pp. 2182-2194, 2013.

[21] A. C. M. Veloo, M. Knoester, J. E. Degener, and E. J. Kuijper, "Comparison of two matrix-assisted laser desorption ionisation-time of flight mass spectrometry methods for the identification of clinically relevant anaerobic bacteria," Clinical Microbiology and Infection, vol. 17, no. 10, pp. 1501-1506, 2011.

[22] D. Martiny, L. Busson, I. Wybo, R. Ait El Haj, A. Dediste, and O. Vandenberg, "Comparison of the Microflex LT and Vitek MS systems for routine identification of bacteria by matrix-assisted laser desorption ionization-time of flight mass spectrometry," Journal of Clinical Microbiology, vol. 50, no. 4, pp. 1313-1325, 2012.

[23] A. Cherkaoui, J. Hibbs, S. Emonet et al., "Comparison of two matrix-assisted laser desorption ionization-time of flight mass spectrometry methods with conventional phenotypic identification for routine identification of bacteria to the species level," Journal of Clinical Microbiology, vol. 48, no. 4, pp. 1169-1175, 2010. 

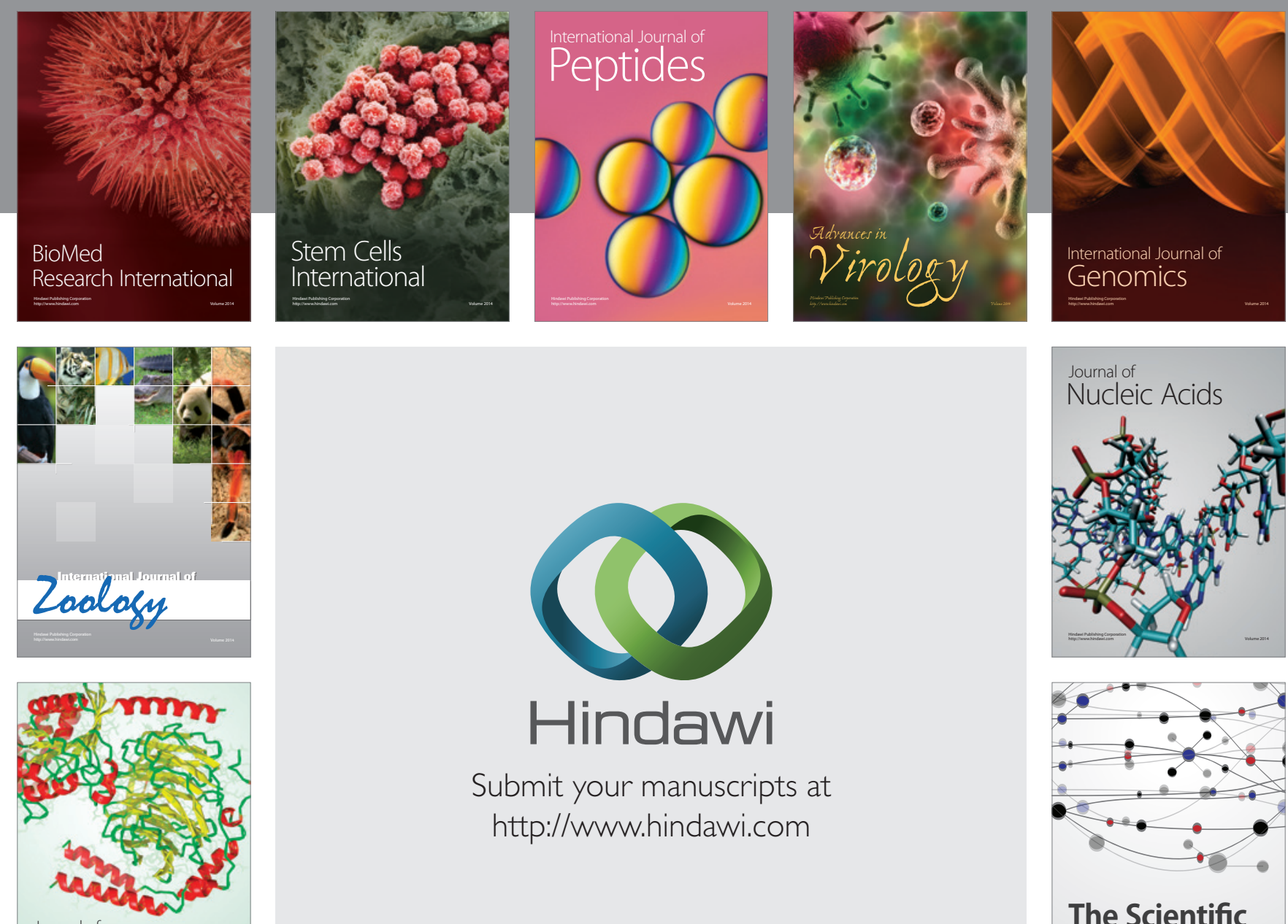

Submit your manuscripts at

http://www.hindawi.com

Journal of
Signal Transduction
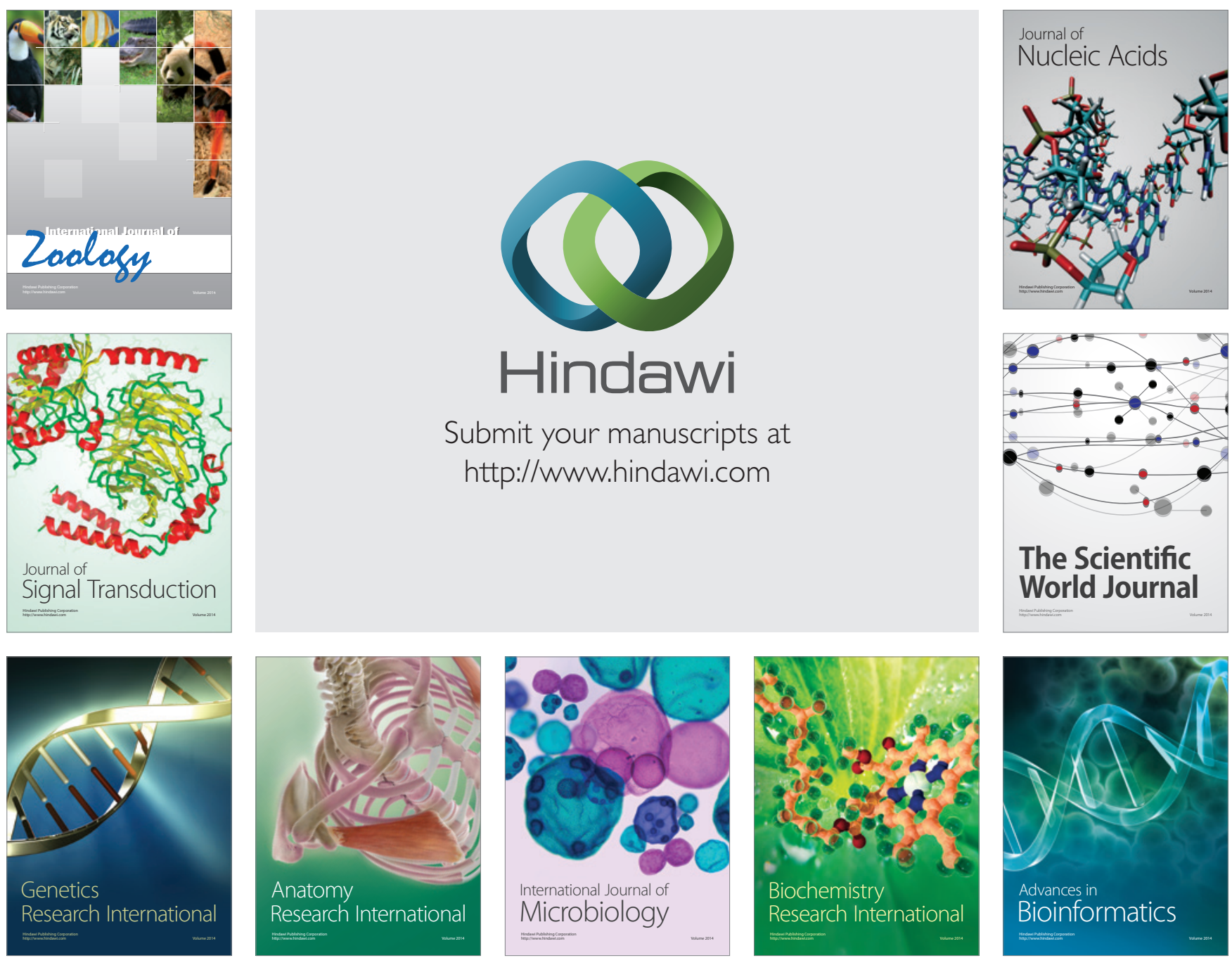

The Scientific World Journal
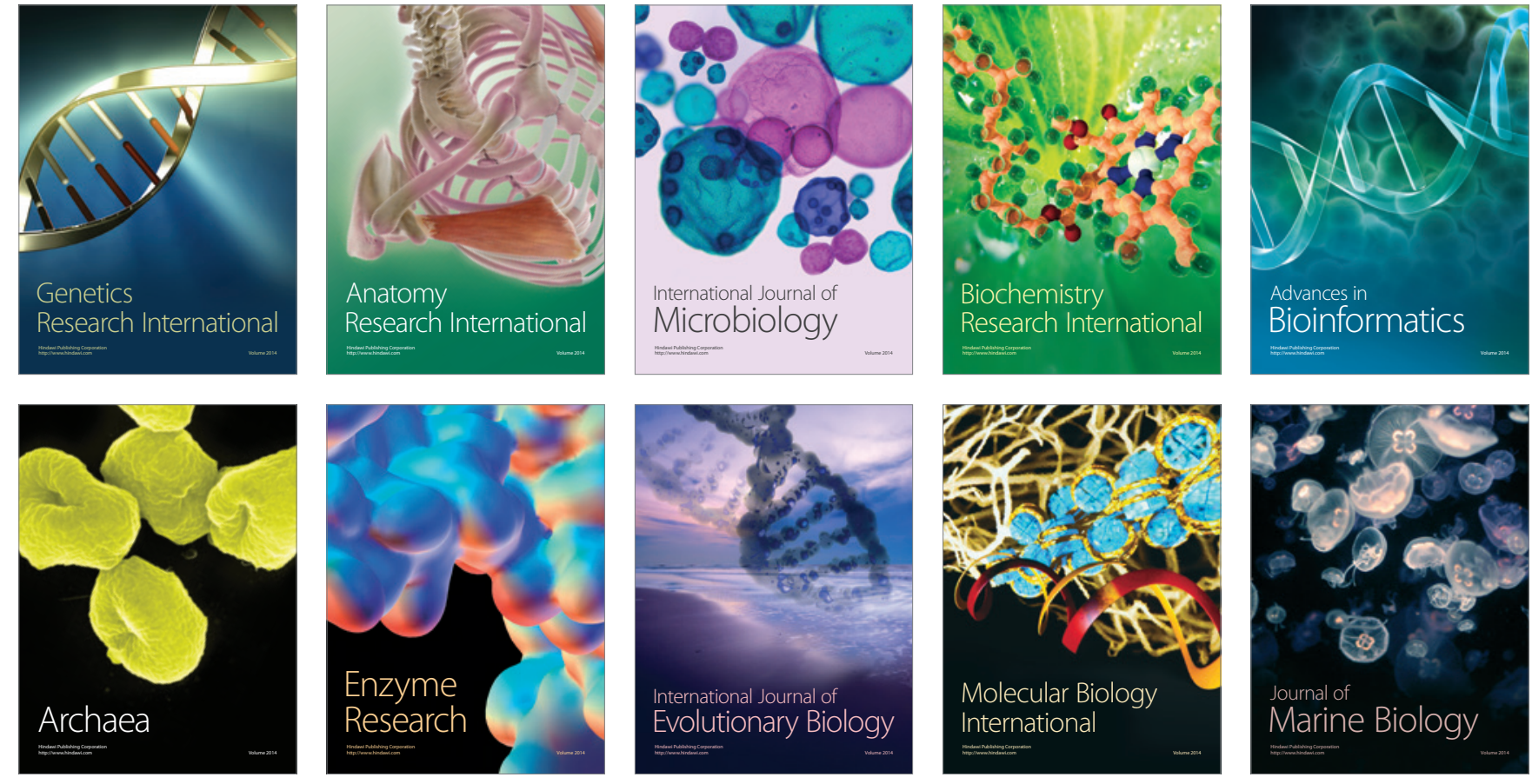